\title{
Self-determination theory and work motivation
}

\author{
MARYLÈNE GAGNÉ ${ }^{1} *$ AND EDWARD L. DECI ${ }^{2}$ \\ ${ }^{1}$ Department of Management, John Molson School of Business, Concordia University, \\ Montreal, Quebec, Canada \\ ${ }^{2}$ Department of Clinical and Social Sciences in Psychology, University of Rochester, Rochester, \\ New York, U.S.A.
}

\begin{abstract}
Summary Cognitive evaluation theory, which explains the effects of extrinsic motivators on intrinsic motivation, received some initial attention in the organizational literature. However, the simple dichotomy between intrinsic and extrinsic motivation made the theory difficult to apply to work settings. Differentiating extrinsic motivation into types that differ in their degree of autonomy led to self-determination theory, which has received widespread attention in the education, health care, and sport domains. This article describes self-determination theory as a theory of work motivation and shows its relevance to theories of organizational behavior. Copyright (C) 2005 John Wiley \& Sons, Ltd.
\end{abstract}

\section{Introduction}

Building on Vroom's (1964) expectancy-valence theory of motivation, Porter and Lawler (1968) proposed a model of intrinsic and extrinsic work motivation. Intrinsic motivation involves people doing an activity because they find it interesting and derive spontaneous satisfaction from the activity itself. Extrinsic motivation, in contrast, requires an instrumentality between the activity and some separable consequences such as tangible or verbal rewards, so satisfaction comes not from the activity itself but rather from the extrinsic consequences to which the activity leads.

Porter and Lawler (1968) advocated structuring the work environment so that effective performance would lead to both intrinsic and extrinsic rewards, which would in turn produce total job satisfaction. This was to be accomplished by enlarging jobs to make them more interesting, and thus more intrinsically rewarding, and by making extrinsic rewards such as higher pay and promotions clearly contingent upon effective performance. Implicit in this model is the assumption that intrinsic and extrinsic rewards are additive, yielding total job satisfaction.

Porter and Lawler's model, Vroom's theory, and other expectancy-valence formulations generated considerable research, much of which confirmed and refined aspects of the approach (see Mitchell,

* Correspondence to: Marylène Gagné, Department of Management, GM 503-49, John Molson School of Business, Concordia University, 1455 de Maisonneuve W., Montreal, Quebec, Canada, H3G 1M8. E-mail: mgagne@jmsb.concordia.ca 
1974). However, one strand of research concerning the additivity of intrinsic and extrinsic motivation was potentially problematic and controversial. Specifically, early studies testing the additivity hypothesis found that tangible extrinsic rewards undermined intrinsic motivation whereas verbal rewards enhanced it (Deci, 1971), thus implying that intrinsic and extrinsic motivation can be both positively and negatively interactive rather than additive. Based on several early experiments, cognitive evaluation theory (CET; Deci, 1975; Deci \& Ryan, 1980) was proposed to explain the effects of extrinsic motivators on intrinsic motivation.

\section{Cognitive Evaluation Theory}

Cognitive evaluation theory suggested first that external factors such as tangible rewards, deadlines (Amabile, DeJong, \& Lepper, 1976), surveillance (Lepper \& Greene, 1975), and evaluations (Smith, 1975) tend to diminish feelings of autonomy, prompt a change in perceived locus of causality (PLOC) from internal to external (deCharms, 1968; Heider, 1958), and undermine intrinsic motivation. In contrast, some external factors such as providing choice about aspects of task engagement tend to enhance feelings of autonomy, prompt a shift in PLOC from external to internal, and increase intrinsic motivation (Zuckerman et al., 1978).

CET further suggested that feelings of competence as well as feelings of autonomy are important for intrinsic motivation. Studies showed that optimally challenging activities were highly intrinsically motivating (e.g., Danner \& Lonky, 1981) and that positive feedback (Deci, 1971) facilitated intrinsic motivation by promoting a sense of competence when people felt responsible for their successful performance (Fisher, 1978; Ryan, 1982). Further, negative feedback which decreased perceived competence was found to undermine both intrinsic and extrinsic motivation, leaving people amotivated (Deci \& Ryan, 1985a).

Underlying these CET propositions was the assumption that people need to feel autonomous and competent, so social-contextual factors that promote feelings of autonomy and competence enhance intrinsic motivation, whereas factors that diminish these feelings undermine intrinsic motivation, leaving people either controlled by contingencies or amotivated.

Spirited debate ensued concerning both the undermining effect and CET (e.g., Calder \& Staw, 1975; Deci, 1976; Deci, Cascio, \& Krusell, 1975; Scott, 1975), leading to numerous laboratory experiments and field studies intended to support, refine, extend, or refute the undermining effect and CET. Eventually, a meta-analysis of 128 laboratory experiments confirmed that, whereas positive feedback enhances intrinsic motivation, tangible rewards significantly undermine it (Deci, Koestner, \& Ryan, 1999).

The Deci et al. (1999) meta-analysis also confirmed CET hypotheses that specified limiting conditions to the undermining effect. Namely, it showed that when rewards were given independent of specific task engagement (as might be the case with a salary) or when the rewards were not anticipated (as might be the case with unexpected bonuses), tangible extrinsic rewards did not undermine intrinsic motivation. Additionally, as found by Ryan, Mims, and Koestner (1983), when rewards were contingent on highquality performance and the interpersonal context was supportive rather than pressuring, tangible rewards enhanced intrinsic motivation relative to a comparison condition with no rewards and no feedback. Notably, however, these performance-contingent rewards did lead to lower intrinsic motivation than a control group that got positive feedback comparable to that conveyed by the rewards. Still, the Deci et al. meta-analysis pointed to possible ways to use rewards without having detrimental effects.

As noted, the undermining of intrinsic motivation has been controversial from the time it first appeared in the literature (Deci, 1971), and even though the Deci et al. (1999) meta-analysis showed 
definitively that tangible rewards undermine intrinsic motivation, recent theories of work motivation have still failed to accept the robustness of the findings. For example, Kehr (2004) suggested that rewards would not undermine intrinsic motivation if they did not deactivate implicit motives related to task enjoyment. However, the statement was pure speculation, and no empirical support for the speculation was provided. Furthermore, support for the hypothesis that expected, tangible rewards administered engagement-contingently or completion-contingently would undermine intrinsic motivation is so strong that, if Kehr's theoretical speculation were correct, it would mean that these types of rewards must, in fact, deactivate implicit enjoyment motives.

Research in line with CET has also shown that contingent, tangible rewards and other extrinsic factors such as competition and evaluations can be detrimental to outcomes such as creativity, cognitive flexibility, and problem solving which have been found to be associated with intrinsic motivation (e.g., Amabile, Goldfarb, \& Brackfield, 1990; McGraw, 1978). For example, McGraw and McCullers (1979) found monetary rewards to decrease cognitive flexibility in problem solving, and Erez, Gopher, and Arzi (1990) showed that monetary rewards decreased performance on a complex task with difficult goals.

\section{The problems with CET as a theory of work motivation}

The undermining of intrinsic motivation by extrinsic rewards and the CET account of that phenomenon received attention in the organizational literature in the 1970s and early 1980s, leading Ambrose and Kulik (1999) to refer to CET as one of seven traditional theories of motivation in organizations. Nonetheless, there are several reasons why that attention soon waned.

First, most studies that tested CET were laboratory experiments rather than organizational studies. Second, it was difficult to incorporate CET propositions into the prevalent behavioral and expectancyvalence approaches. Third, and more practically, many activities in work organizations are not intrinsically interesting and the use of strategies such as participation to enhance intrinsic motivation is not always feasible. Fourth, most people who work have to earn money, so using monetary rewards as a central motivational strategy seems practical and appealing. Fifth, CET seemed to imply that managers and management theorists would have to focus on one or the other- that is, either on promoting intrinsic motivation through participation and empowerment while minimizing the use of extrinsic factors or, alternatively, on using rewards and other extrinsic contingencies to maximize extrinsic motivation while ignoring the importance of intrinsic motivation.

In 1985 Ryan, Connell, and Deci first presented a differentiated analysis of extrinsic motivation using the concepts of internalization, which directly addresses the last of the above critiques of CET and also has implications for some of the others. Internalization refers to 'taking in' a behavioral regulation and the value that underlies it. The Ryan et al. theorizing, which explains how extrinsically motivated behavior can become autonomous, together with research on individual differences in causality orientations (Deci \& Ryan, 1985b), led to the formulation of self-determination theory (SDT) (Deci \& Ryan, 1985a, 2000; Ryan \& Deci, 2000), which incorporated CET but is much broader in scope. In this paper, we present SDT, review the research on which it was based, compare it to other work motivation theories, lay out a research agenda, and discuss its relevance for organizational behavior and management.

\section{Self-Determination Theory}

Central to SDT is the distinction between autonomous motivation and controlled motivation. Autonomy involves acting with a sense of volition and having the experience of choice. In the words 
of philosophers such as Dworkin (1988), autonomy means endorsing one's actions at the highest level of reflection. Intrinsic motivation is an example of autonomous motivation. When people engage an activity because they find it interesting, they are doing the activity wholly volitionally (e.g., I work because it is fun). In contrast, being controlled involves acting with a sense of pressure, a sense of having to engage in the actions. The use of extrinsic rewards in the early experiments was found to induce controlled motivation (e.g., Deci, 1971). SDT postulates that autonomous and controlled motivations differ in terms of both their underlying regulatory processes and their accompanying experiences, and it further suggests that behaviors can be characterized in terms of the degree to which they are autonomous versus controlled. Autonomous motivation and controlled motivation are both intentional, and together they stand in contrast to amotivation, which involves a lack of intention and motivation.

\section{Extrinsic motivation and the autonomy continuum}

Intrinsically motivated behavior, which is propelled by people's interest in the activity itself, is prototypically autonomous. However, an important aspect of SDT is the proposition that extrinsic motivation can vary in the degree to which it is autonomous versus controlled. Activities that are not interesting (i.e., that are not intrinsically motivating) require extrinsic motivation, so their initial enactment depends upon the perception of a contingency between the behavior and a desired consequence such as implicit approval or tangible rewards. Within SDT, when a behavior is so motivated it is said to be externally regulated - that is, initiated and maintained by contingencies external to the person. This is the classic type of extrinsic motivation and is a prototype of controlled motivation. When externally regulated, people act with the intention of obtaining a desired consequence or avoiding an undesired one, so they are energized into action only when the action is instrumental to those ends (e.g., I work when the boss is watching). External regulation is the type of extrinsic motivation that was considered when extrinsic motivation was contrasted with intrinsic motivation.

Other types of extrinsic motivation result when a behavioral regulation and the value associated with it have been internalized. Internalization is defined as people taking in values, attitudes, or regulatory structures, such that the external regulation of a behavior is transformed into an internal regulation and thus no longer requires the presence of an external contingency (thus, I work even when the boss is not watching). However, although most theories of internalization view it as a dichotomy - that is, a regulation either is external to the person or has been internalized-SDT posits a controlled-to-autonomous continuum to describe the degree to which an external regulation has been internalized. The more fully it has been internalized, the more autonomous will be the subsequent, extrinsically motivated behavior. According to SDT, internalization is an overarching term that refers to three different processes: introjection, identification, and integration.

A regulation that has been taken in by the person but has not been accepted as his or her own is said to be introjected and provides the basis for introjected regulation. With this type of regulation, it is as if the regulation were controlling the person. Examples of introjected regulation include contingent selfesteem, which pressures people to behave in order to feel worthy, and ego involvement, which pressures people to behave in order to buttress their fragile egos (deCharms, 1968; Ryan, 1982). Introjected regulation is particularly interesting because the regulation is within the person but is a relatively controlled form of internalized extrinsic motivation (e.g., I work because it makes me feel like a worthy person).

Being autonomously extrinsically motivated requires that people identify with the value of a behavior for their own self-selected goals. With identified regulation, people feel greater freedom and volition because the behavior is more congruent with their personal goals and identities. They perceive the 
cause of their behavior to have an internal PLOC — that is, to reflect an aspect of themselves. If nurses strongly value their patients' comfort and health and understand the importance of doing their share of the unpleasant tasks for the patients' well-being, the nurses would feel relatively autonomous while performing such tasks (e.g., bathing patients), even though the activities are not intrinsically interesting.

The fullest type of internalization, which allows extrinsic motivation to be truly autonomous or volitional, involves the integration of an identification with other aspects of oneself-that is, with other identifications, interests, and values. With integrated regulation, people have a full sense that the behavior is an integral part of who they are, that it emanates from their sense of self and is thus self-determined. If integrated, the nurses would not only identify with the importance of the activities for maintaining their patients' comfort and health, but regulation of the activities would be integrated with other aspects of their jobs and lives. Thus, the profession of nurse would be more central to their identity, they would be more likely to act in ways that are consistent with caring for people more generally, and they could come to appreciate the importance of doing uninteresting activities.

Integrated regulation is theorized to represent the most developmentally advanced form of extrinsic motivation, and it shares some qualities with the other type of autonomous motivation, namely, intrinsic motivation. Integrated regulation does not, however, become intrinsic motivation but is still considered extrinsic motivation (albeit an autonomous form of it) because the motivation is characterized not by the person being interested in the activity but rather by the activity being instrumentally important for personal goals. In short, intrinsic motivation and integrated extrinsic motivation are the two different types of autonomous motivation (with identified extrinsic motivation being relatively autonomous).

It is important to note that the SDT model of internalization is not a stage theory and does not suggest that people must invariantly move through these 'stages' with respect to particular behaviors. Rather, the theory describes these types of regulation in order to index the extent to which people have integrated the regulation of a behavior or class of behaviors. As such, SDT proposes that, under optimal conditions, people can, at any time, fully integrate a new regulation, or can integrate an existing regulation that had been only partially internalized.

To summarize, SDT posits a self-determination continuum (see Figure 1). It ranges from amotivation, which is wholly lacking in self-determination, to intrinsic motivation, which is invariantly selfdetermined. Between amotivation and intrinsic motivation, along this descriptive continuum, are the four types of extrinsic motivation, with external being the most controlled (and thus the least selfdetermined) type of extrinsic motivation, and introjected, identified, and integrated being progressively more self-determined.

\section{Assessing intrinsic and extrinsic motivation}

Intrinsic motivation and each type of extrinsic motivation are reflected in different reasons for behaving, and these reasons provide a means for assessing the types of motivation (Ryan \& Connell, 1989). The Ryan and Connell approach has spawned a family of questionnaires that involve asking participants why they would do particular behaviors that are relevant to the situation being researched. Then, participants are presented with various reasons for doing the behaviors that reflect intrinsic motivation or one of the types of extrinsic motivation. Participants rate the degree to which each is true for them. Examples of external reasons are doing the behavior to get a raise or so the boss won't be upset, whereas examples of introjected reasons are behaving to avoid guilt or to feel worthy. Identified and integrated reasons involve behaving because people personally value the behavior and have fully accepted its importance for their self-selected goals and their well-being. Intrinsic motivation involves 


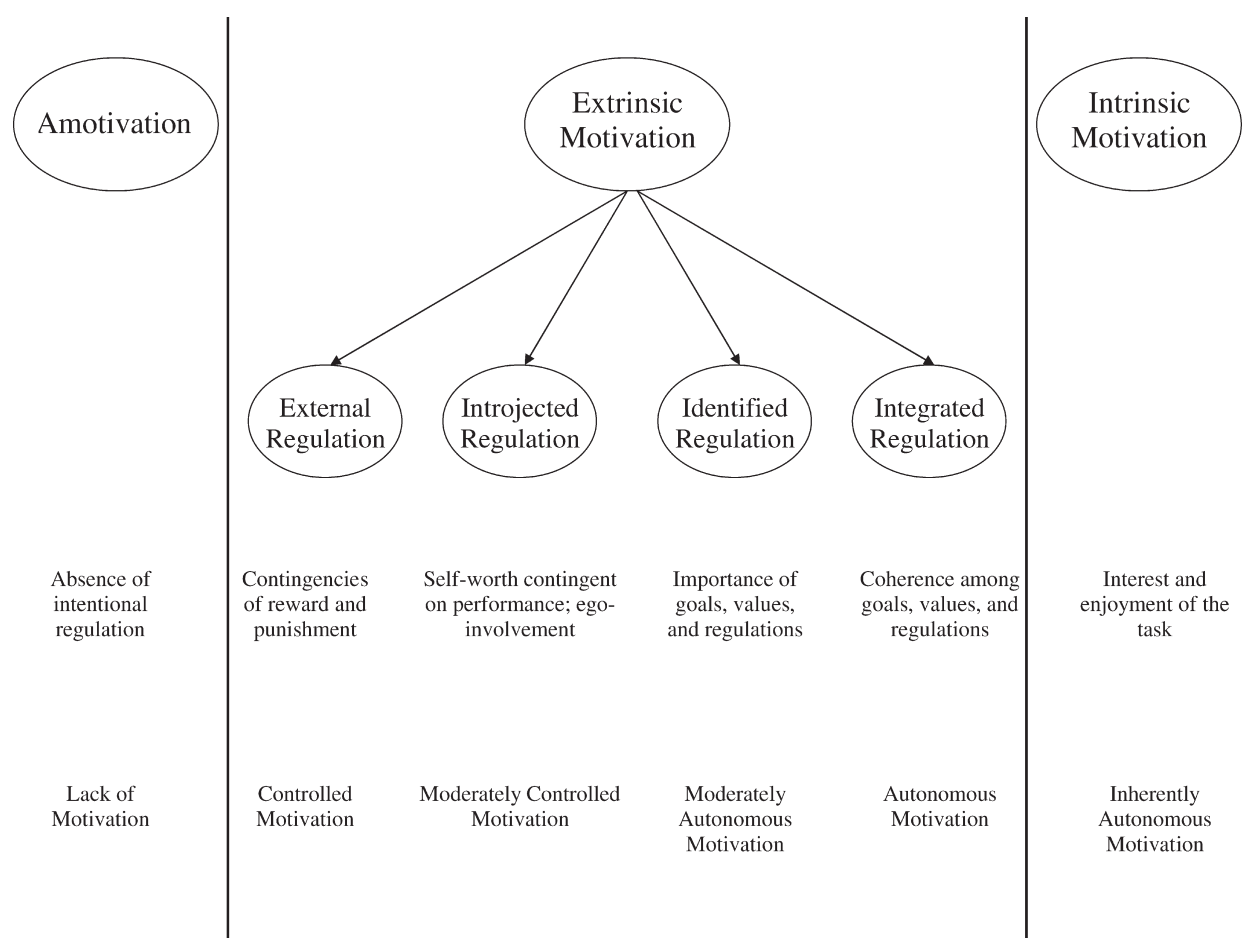

Figure 1. The self-determination continuum showing amotivation, which is wholly lacking in self-determination; the types of extrinsic motivation, which vary in their degree of self-determination; and intrinsic motivation, which is invariantly self-determined. Also shown are the nature of the regulation for each and its placement along the continuum indexing the degree to which each represents autonomous motivation

behaving because the activities are interesting, and amotivation involves having no intentions for the behavior and not really knowing why one is doing it. Research using this assessment strategy has confirmed that, in domains such as education (Williams \& Deci, 1996), sports (Vallerand \& Fortier, 1998), and health care (Williams et al., 1996), the types of regulation adhere to a quasi-simplex pattern, which means that each subscale correlates most positively with the subscales closest to it and less positively or more negatively with subscales farther from it. This pattern is consistent with the SDT assertion of an underlying control-to-autonomy continuum. Accordingly, the subscales can be used individually to predict outcomes, or they can be combined algebraically to form a relative autonomy index (Grolnick \& Ryan, 1987).

\section{Basic psychological needs}

According to the meta-theory that underlies SDT, both intrinsic motivation and internalization (which in its fullest form is integration) are natural processes that require nutriments to function optimally. The theory then postulates that satisfaction of basic psychological needs provides the nutriments for intrinsic motivation and internalization. We argued earlier that the needs for competence and autonomy underlie intrinsic motivation - that people need to feel competent and autonomous to maintain their intrinsic motivation - and experiments were reviewed that provided support for that proposition. According to SDT, satisfaction of these two needs are also necessary for internalization to operate 
effectively, but a third basic need - the need for relatedness - is also crucial for internalization (e.g., Baumeister \& Leary, 1995). More specifically, SDT postulates that when people experience satisfaction of the needs for relatedness and competence with respect to a behavior, they will tend to internalize its value and regulation, but the degree of satisfaction of the need for autonomy is what distinguishes whether identification or integration, rather than just introjection, will occur. Stated differently, satisfaction of the needs to be connected to others and to be effective in the social world support people's tendency to internalize the values and regulatory processes that are ambient in their world. However, such internalization does not ensure that the resulting behavior will be autonomous. Satisfaction of the need for autonomy while internalizing the behavior is also necessary for the value and regulation to be more fully internalized so the subsequent enactment of the behavior will be autonomous.

The concept of psychological needs has been central to organizational behavior for decades, although there has been some debate about the utility of the concept (e.g., Salancik \& Pfeffer, 1977). When used in organizational theories, needs have typically been treated as individual differences; that is, people are viewed as differing in the strength of particular needs. From that perspective, need strength is assessed and used either directly or in interaction with job characteristics to predict motivation, job satisfaction, and work outcomes (e.g., Hackman \& Lawler, 1971; McClelland \& Burnham, 1976).

SDT defines needs differently. Specifically, consistent with the positions of psychologists such as Harlow (1958) and White (1959), SDT defines needs as universal necessities, as the nutriments that are essential for optimal human development and integrity (Ryan, Sheldon, Kasser, \& Deci, 1996). According to this definition, something is a need only to the extent that its satisfaction promotes psychological health and its thwarting undermines psychological health. Using this definition, the needs for competence, autonomy, and relatedness are considered important for all individuals, so SDT research focuses not on the consequences of the strength of those needs for different individuals, but rather on the consequences of the extent to which individuals are able to satisfy the needs within social environments.

Many studies guided by SDT have provided support for this perspective (see Deci \& Ryan, 2000, for a review). For example, Reis et al. (2000) examined satisfaction of the three basic psychological needs in people's ongoing lives. Using both individual-difference and daily-diary procedures they predicted well-being from satisfaction of all three needs. They found first that trait measures of autonomy, competence, and relatedness, as well as aggregates of the daily measures of autonomy, competence, and relatedness, all made independent contributions to well-being indices, thus confirming these relations at the between-person level. Then, after between-person variance was removed, daily fluctuations in satisfaction of the three needs independently predicted daily fluctuations in well-being. Thus, the study showed an association between need satisfaction and well-being at the within-person as well as between-person levels of analysis, with independent contributions being made by satisfaction of each basic need. Similarly, Gagné, Ryan, and Bargmann (2003) found that gymnasts' daily experiences of satisfaction of the basic needs predicted change in well-being over the 4 weeks of the study.

With respect to organizations, we argue, based largely on laboratory experiments and field research in other domains, that work climates that promote satisfaction of the three basic psychological needs will enhance employees' intrinsic motivation and promote full internalization of extrinsic motivation and that this will in turn yield the important work outcomes of (1) persistence and maintained behavior change; (2) effective performance, particularly on tasks requiring creativity, cognitive flexibility, and conceptual understanding; (3) job satisfaction; (4) positive work-related attitudes; (5) organizational citizenship behaviors; and (6) psychological adjustment and well-being.

There has been some organizational research that provides support for this view and will be discussed more fully later in the paper. For example, in a study conducted in Bulgaria and the United 
States, Deci et al. (2001) assessed satisfaction of employees' needs for competence, autonomy, and relatedness at work and found direct positive relations in both countries between the degree of need satisfaction and both work engagement and well-being on the job. Baard, Deci, and Ryan (2004) found relations between satisfaction of these needs and employees' performance evaluations. Further, there has been some research that relates SDT concepts to those from theories of organizational commitment, and they too will be discussed later.

\section{Social contexts and internalization}

One the most important reasons for postulating that there are basic psychological needs, defined as we have done, is that they provide the basis for predicting which aspects of a social context will support intrinsic motivation and facilitate internalization of extrinsic motivation. For example, a study by Grolnick and Ryan (1989) confirmed that mothers' and fathers' provision of supports for competence, relatedness, and autonomy with respect to their children's homework predicted the children's maintaining intrinsic motivation for school work and internalizing the importance of school-related activities, which in turn predicted the children's school performance and adjustment.

We noted earlier that autonomy support is the most important social-contextual factor for predicting identification and integration, and thus autonomous behavior. Indeed, several studies have found autonomy-supportive interpersonal environments to promote internalization and integration of extrinsic motivation and in turn positive outcomes. A study by Black and Deci (2000) showed that the autonomy supportiveness of instructors in a university organic chemistry course predicted not only increases in autonomous motivation over the semester but also course grades after controlling for SAT scores and GPAs. The finding was especially strong for students with initially low levels of autonomous motivation. A study of internalization of values by medical students provided further support for SDT by revealing that when the instructors were more autonomy supportive students showed greater internalization of the values presented in the course and this predicted autonomous, value-congruent behaviors 6 months after the course ended (Williams \& Deci, 1996). Finally, field studies in medical clinics have shown that health care providers' autonomy support predicted patients' becoming more autonomously motivated for health behavior change, which in turn led to greater maintained health behavior change (see Williams, Deci, \& Ryan, 1998, for a review).

To examine specific factors that constitute autonomy support and facilitate internalization of extrinsic motivation, Deci, Eghrari, Patrick, and Leone (1994) performed a laboratory experiment. They found that three specific factors - a meaningful rationale for doing the task, acknowledgment that people might not find the activity interesting, and an emphasis on choice rather than control-led to greater internalization, assessed both by the amount of time participants spent with the task during a subsequent free-choice period and by their self-reported attitudes toward the task.

There was another important finding in the study. Deci et al. (1994) divided participants into two groups: those for whom two or three of the facilitating factors were present and those for whom none or one of the factors was present. In both groups, there was some internalization, although of course there was more internalization in the group with more facilitating factors. The two groups were created to test the hypothesis that the type of internalization would be different when different amounts of autonomy support were provided. Results showed that in conditions with two or three facilitating factors the internalization was integrated as reflected in significant positive correlations between the amount of subsequent behavior and self-reports of valuing the task and feeling free while doing it; whereas in conditions with zero or one facilitating factor the internalization was introjected as reflected by negative correlations between the behavior and the self-report variables. In the less autonomy-supportive conditions, people who behaved did so in spite of feeling less free and valuing 
the activity less. Joussemet, Koestner, Lekes, and Houlfort (2004) recently found comparable results in a study with children. Thus, autonomy-supportive conditions not only led to more internalization of extrinsic motivation but also ensured that the internalization that occurred was more integrated rather than just introjected.

It is interesting that the factors shown by Deci et al. (1994) to facilitate integration bear similarity to the elements of communication, empathy and concern, and participation and involvement which Kirkpatrick (1985) said were critical to promote acceptance of organizational change, a view supported by Gagné, Koestner, and Zuckerman (2000).

In sum, field and lab studies have found that supports for the basic needs for competence, relatedness, and autonomy facilitate internalization and integration of extrinsic motivation, with supports for autonomy being the most important for facilitating integration. Supports for autonomy fall within two general categories: (1) specific factors in the social context, such as choice and meaningful positive feedback, which can be thought of as being analogous to specific aspects of job contents and contexts; and (2) the interpersonal ambience, which can be thought of as being analogous to the organizational climate and managers' interpersonal styles.

There is considerable similarity between the social-contextual factors that maintain intrinsic motivation and those that facilitate integration of extrinsic motivation. Specifically, autonomy-supportive climates, as well as such specific factors as choice and acknowledgement, promote both types of autonomous motivation. However, there are two notable differences between the factors that maintain intrinsic motivation and those that facilitate internalization. First, people do not necessarily require structures, limits, or contingencies to maintain intrinsic motivation, but these are essential elements for internalization because it is they that get internalized. Second, internalization is facilitated by explicit or implicit endorsement of behaviors by significant others, whereas that is less important for maintaining intrinsic motivation. Noting the differences between the conditions that support intrinsic motivation and those that promote internalization is important because autonomous (i.e., well-internalized) extrinsic motivation predicts somewhat different outcomes from intrinsic motivation. Specifically, as we will see later, autonomous extrinsic motivation is more predictive than is intrinsic motivation for behaviors that are not themselves interesting and require discipline and explicit effort (Koestner \& Losier, 2002).

\section{Individual differences: general causality orientations}

SDT also addresses individual differences in people's orientations toward the initiation and regulation of their behavior. Referred to as general causality orientations (Deci \& Ryan, 1985b), they index the degree to which people are autonomy oriented, control oriented, and impersonally oriented. The autonomy orientation reflects a general tendency to experience social contexts as autonomy supportive and to be self-determined; the control orientation reflects a general tendency to experience social contexts as controlling and to be controlled; and the impersonal orientation reflects the general tendency to be amotivated. Research (e.g., Deci \& Ryan, 1985b; Hodgins, Koestner, \& Duncan, 1996; Koestner, Bernieri, \& Zuckerman, 1992; Williams et al., 1996; Vallerand, 1997) has shown that the autonomy orientation is positively related to self-actualization, self-esteem, ego development, integration in personality, and satisfying interpersonal relationships; that the control orientation is associated with public self-consciousness, the Type A behavior pattern, defensive functioning, and placing high importance on pay and other extrinsic motivators; and that the impersonal orientation is related to external locus of control (i.e., the belief that one can not control outcomes) and to self-derogation and depression. 


\section{In sum: an overview of the structure of SDT}

SDT distinguishes between amotivation (i.e., lack of motivation) and motivation. Amotivation involves not having an intention to act, whereas motivation involves intentionality. Within motivation, SDT distinguishes between autonomous motivation and controlled motivation. Autonomous motivation includes intrinsic motivation and well-internalized extrinsic motivation. Thus, being autonomously motivated means being motivated by one's interest in an activity (i.e., intrinsic motivation) and/or because the value and regulation of the activity have been integrated within one's self (i.e., integrated extrinsic motivation). Controlled motivation consists of external regulation (the only type of extrinsic motivation that was considered when research focused on the dichotomy between intrinsic and extrinsic motivation) and introjected extrinsic motivation. Thus, the degree of one's controlled motivation reflects the degree to which one feels coerced or seduced by external contingencies or by their introjected counterparts.

The concepts of autonomous motivation, controlled motivation, and amotivation concern a person's relation to an activity (e.g., writing a report) or sets of activities (e.g., doing one's job). Thus, they are relatively state-like motivational concepts. These motivational variables are predicted from both (1) aspects of the social environment, including both aspects of the job and the work climate, that can be characterized as autonomy supportive, controlling, or amotivating; and (2) individual differences in causality orientations, namely, the autonomous orientation, the controlled orientation, and the impersonal orientation, which are more trait-like concepts. As such, the degree to which people are autonomously motivated for their jobs would be predicted from the supports for autonomy in their work contexts and their own autonomous causality orientation. Similarly, the degree of their controlled motivation would be predicted from the control in the work context and their own controlled causality orientation. People's amotivation would be predicted from the amotivating aspect of their work context and from their impersonal orientation. Finally, the concept of basic psychological needs for competence, relatedness, and autonomy specifies the nutriments that are necessary within a social environment for it to be classified as autonomy supportive, controlling, or amotivating.

\section{The Relation of SDT to Other Theories of Work Motivation}

Within the field of work motivation, as in the broader field of motivated or regulated behavior, much of the work falls within the cognitive tradition that evolved out of the work of Lewin (1936) and Tolman (1932). Within that tradition, many theories have been greatly influenced by the cybernetic approach (e.g., Miller, Galanter, and Pribram, 1960) and the expectancy-valence approach (e.g., Atkinson, 1964; Vroom, 1964). Although the theories are highly varied, there is one aspect that is common to most of them; namely, that motivation for action is treated as a unitary concept that varies in amount rather than kind. In other words, the total motivation a person has may be determined by various factors but represents a single variable that provides the basis for making predictions. Thus, the central motivational issue in most theories is the amount of total motivation a person has for a task, so the type of motivation is not considered in making predictions. Even theories such as Porter and Lawler's (1968) that distinguish intrinsic motivation and extrinsic motivation consider them to be additive, with total motivation being the critical motivational predictor.

The primary difference between SDT and most other work motivation theories is that the focus of SDT is on the relative strength of autonomous versus controlled motivation, rather than on the total amount of motivation. We maintain that it is important for a motivational theory to differentiate types 
of motivation and to use them in making predictions because research has shown that, whereas autonomous motivation facilitates effective performance and well-being, controlled motivation can detract from those outcomes, particularly if the task requires creativity, cognitive flexibility, or deep processing of information. In this section, we briefly consider several theories of work motivation to highlight differences between those theories and SDT.

\section{Goal-setting theory}

Locke and Latham's (1990) goal-setting theory has had a substantial impact in the field of work motivation. Integrating earlier work by Locke (1968) with aspects of self-efficacy theory (Bandura, 1986), Locke and Latham outlined a general goal-setting theory of motivation. They suggested that people's goal representations are the efficient causes of behavior and that people's performance will be maximized when (1) they set specific, difficult goals that have high valence and (2) they understand what behaviors will lead to the goals and feel competent to do those behaviors. This theory, which has received substantial empirical support, is an example of the theories that do not differentiate kinds of motivation. Thus, characteristics of goals (e.g., their difficulty) are used to predict work outcomes, but no attention is given to the fact that different goal contents and different types of regulation of goal pursuits lead to different qualities of performance (e.g., Sheldon \& Elliot, 1999; Sheldon, Ryan, Deci, $\&$ Kasser, 2004). Furthermore, Locke and Latham do not differentiate the concept of performance in order to examine differences between the types of goals and regulations that predict algorithmic versus heuristic performance. In contrast, SDT proposes that autonomous motivation and intrinsic goals are better predictors of effective performance on heuristic tasks (Vansteenkiste et al., 2004), whereas the two types of motivation do not differ in predicting effective algorithmic performance, particularly over the long term (see, for example, McGraw, 1978). Thus, SDT maintains that differentiating motivation and goals provides an integrated means of relating characteristics of tasks and interpersonal environments, as well as individual differences, to types of performance and well-being.

There is a noteworthy point of convergence between the Locke and Latham approach and ours. Specifically, Deci et al. (1994) found that a 'meaningful rationale' is one of the important factors that facilitates integrated internalization, and Latham, Erez, and Locke (1988) found that it facilitates goal acceptance.

\section{Action regulation theory}

For the past quarter century a number of scholars working primarily in Germany have used action theory to examine motivation in work organizations as well as other settings. Strongly influenced by the cybernetic approach, the theory uses the concept of goals and emphasizes the mechanisms that keep people effectively focused on goal-directed action (e.g., Frese \& Sabini, 1991; Hacker, 1994). The theory includes the concept of decision latitude, which it equates with autonomy. It then suggests that maximal motivation and action result when there is considerable decision latitude, which allows workers to set their own goals. Hacker went so far as to say that greater decision latitude promotes greater intrinsic motivation, but the theory does not make differential predictions for intrinsic and extrinsic motivation. Working with this general approach, Frese (1989) suggested that control over one's behavior (i.e., decision latitude), combined with optimal complexity of the task and without undue complicatedness, leads to optimal performance and well-being. Subsequently, Frese (2001) outlined a model in which a variety of personality factors, skills, and environmental supports were theorized to lead to personal initiative, which is essentially a single motivation variable that is then used to 
predict work outcomes. In contrast, SDT explicitly uses the differentiated concepts of autonomous and controlled types of motivation to make predictions about effective performance and psychological health. Furthermore, SDT views decision latitude to be just one factor that is important for supporting autonomy, with others such as the interpersonal style of managers also being extremely important.

\section{Kanfer's task-specific motivation}

Kanfer (1987; Kanfer \& Ackerman, 1989, 2004) has outlined a theory of work motivation that falls in the same general cognitive tradition as action theory. It uses the interaction of motivation and individual differences in abilities as a primary basis for predicting work performance. Motivation is characterized in terms of two cognitive resource allocation processes, referred to as distal and proximal. Distal factors concern mechanisms such as the utility to the person of doing the task and the perceived instrumentality of expending effort for effective performance. When the target activities are relatively complex and require sustained effort, proximal factors such as self-monitoring and self-regulation are critical for performance and competence development.

As with action theory, Kanfer's approach has a unitary conception of motivation that is affected by both distal and proximal factors. Further, it is heavily focused on the mechanisms that keep people focused on task performance and skill development. With the unitary conception of motivation and the focus on how goals are attained, Kanfer's theory is not well equipped to predict types of performance (algorithmic and heuristic) and does not give consideration to the affective or well-being outcomes that accompany different types of motivation and performance. In contrast, SDT is less concerned with the mechanisms that describe how a goal is achieved, but it does give central concern to predicting types of performance and it places great importance on the prediction of well-being outcomes as well as performance outcomes.

\section{Job characteristics theory}

Hackman and Oldham (1980) argued that the most effective means of motivating individuals is through the optimal design of jobs. Their theory of job characteristics focuses on facilitating high internal work motivation, which bears considerable relation to autonomous motivation, although the theory does not distinguish introjected forms of internal motivation from identified, integrated, and intrinsic forms, so it does not have the means for examining negative consequences that are associated with the introjected type of internal motivation. The authors proposed that the means for increasing internal work motivation is to design jobs so they will (1) provide variety, involve completion of a whole, and have a positive impact on the lives of others; (2) afford considerable freedom and discretion to the employee (what action theorists refer to as decision latitude); and (3) provide meaningful performance feedback. The authors further explain that individual differences in the strength of growth needs moderate the degree to which these job characteristics have a positive impact on job performance.

Self-determination theory concurs that these job characteristics will tend to promote autonomous motivation, and research is consistent with this view (e.g., Gagné, Senécal, \& Koestner, 1997). However, SDT differs in three major ways from Hackman and Oldham's approach. First, SDT focuses not only on job characteristics such as choice and constructive feedback as one way to influence autonomous motivation, but it also suggests that the interpersonal style of supervisors and managers is important. Research by Deci, Connell, and Ryan (1989) found that when managers were trained to be more autonomy supportive - that is, to understand subordinates' perspectives, encourage their initiative, and provide feedback in an autonomy-supportive rather than controlling way-their subordinates 
became more trusting of the organization and displayed more positive work-related attitudes. Second, SDT does not focus on need strength as an individual difference but instead considers causality orientations as the individual difference. This difference in type of individual differences is important because it suggests that everyone needs to satisfy the needs for competence, autonomy, and relatedness and will show positive consequences when they do. Third, because Hackman and Oldham focus only on one type of motivation (i.e., internal motivation), their approach does not consider issues such as the interplay and trade-offs between internal motivation and controlled motivation. Pertinent to this is the finding that jobs with high motivating potential scores were associated with enhanced psychological states and better outcomes only for workers who perceived that pay and promotion were not contingent on performance (Johns, Xie, \& Fang, 1992).

\section{Needs and motives: Maslow, Herzberg, and Alderfer}

The theories of Maslow (1954), Herzberg (1966), and Alderfer (1972) are considered classics in organizational behavior. In the work of Maslow and Alderfer there are five and three classes of needs, respectively, organized in a hierarchy from the basic, lower-order needs such as the physiological drives to higher-order needs for actualization or growth. In the work of Herzberg there are just two categories of motives, typically referred to either as satisfiers and motivators or extrinsic and intrinsic motives, with the motivators (i.e., intrinsic motives) being considered higher order. There are some aspects of these theories that are consistent with SDT. For example, like these previous theorists, we use a concept of psychological needs and we hypothesize that satisfaction of these needs will be associated with more effective performance and well-being, and we, like these previous theorists, tend to endorse participative approaches that allow people to experience satisfaction of their psychological needs.

However, there are also important differences between SDT and these other theories. Whereas SDT posits basic psychological needs that must be satisfied for optimal functioning and well-being, it also elaborates regulatory processes that underlie the direction of behavior. Thus, whereas the other theories focus primarily on the energizers of motivated action, SDT addresses both of the fundamental motivation questions, namely how behavior is energized and how it is directed. Furthermore, SDT differs from the others in the way it has evolved and is formulated. Specifically, it has evolved over three decades using an empirical approach in which each proposition has received empirical confirmation before being incorporated into the theory. In addition, many experimental paradigms and psychometric instruments have been developed along with the theory in order to allow for continued tests and elaborations. Thus, SDT is formulated in a way that suggests a wide range of researchable questions, and it provides methods for testing many of these questions. As such, although Miner (1990) criticized the 'humanistic' theories because of their lack of empirical support, SDT is one theory that would fall within Miner's definition of humanistic but has also received an enormous amount of empirical validation.

\section{Kelman's theory of internalization and the concept of identification}

Kelman (1958) presented a differentiated theory of internalization or attitude change positing that a person's attitude-related behavior can either be compliant and short lived or can be enduringly influenced by others if (1) the person identifies with the others, or (2) the behavior is congruent with the person's values. In this theory, the focus of identification is with other people, and once a person has identified with others the person will be inclined to engage in all the behaviors exhibited or endorsed 
by those others. In contrast, in SDT, the focus of internalization is on values and behavioral regulations and on the degree to which they have been fully integrated with one's self. Thus, SDT would speak not so much of identifying with another but rather of identifying with values and behaviors that are endorsed by another.

There is another important difference. Whereas Kelman's approach suggests that identifying with another person would lead people to persistently engage in behaviors that are performed or endorsed by that other, we maintain that, were people to identify with another, the persisting behaviors that result could either be relatively controlled or relatively autonomous. In other words, although an identification or perceived connection with another could prompt a person's behavior, the behavioral regulation could be either (1) controlled (i.e., performed so the person would receive real or imagined approval from that other) or (2) autonomous (i.e., performed based on the individual's understanding and acceptance of the personal importance of the behavior for himself or herself). Thus, behavior that is said to be regulated by identification in Kelman's use of that term could correspond to regulation that results from either introjection or identification using SDT's definitions of the terms.

It is worth noting that the concept of identification is central to a recent theory of work motivation presented by Ellemers, de Gilder, and Haslam (2004). These authors focused on identification with groups, suggesting that individuals' strong identification with a group facilitates their motivation in accord with the group's goals and in turn facilitates the group's performance. As with Kelman's (1958) concept of identifying with an individual, the Ellemers et al. conceptualization of identifying with a group does not address whether the group identification is autonomous or controlled (Ryan \& Deci, 2002). As such, it is not able to make the differentiated predictions about performance and wellbeing that are central to SDT.

\section{Organizational commitment}

Two theories have presented differentiated views of organizational commitment. First, O'Reilly and Chatman (1986) used Kelman's (1958) typology to distinguish three forms of organizational commitment, including (a) identification with the organization, (b) internalization of the organization's values, and (c) compliance. Theoretically, O'Reilly and Chatman's compliance is related to SDT's external regulation. Further, as suggested above, their concepts of identification and internalization relate to the internal types of motivation in SDT - that is, to autonomous extrinsic motivation, as well as to introjected motivation (which is not autonomous). To test this, Gagné and Koestner (2002) did a study in which they assessed the SDT concepts of external, introjected, identified, and intrinsic motivation, as well as O'Reilly and Chatman's (1986) identification and internalization. The researchers found, as expected, that the two types of commitment correlated strongly with intrinsic motivation and identified regulation ( $r$ 's ranged from 0.46 to 0.58 ), and that they also correlated significantly with introjected regulation $(r$ 's $=0.36$ and 0.39$)$. Neither identification nor internalization correlated with external regulation. The researchers then combined the four subscales of the motivation measure to form a relative autonomy index as described by Ryan and Connell (1989), and they found, using cross-lag correlations, that Time 1 relative autonomy predicted Time 2 commitment (the combination of identification and internalization), but Time 1 commitment did not predict Time 2 autonomous motivation. This suggests that autonomous motivation may provide an important part of the basis for these types of commitment.

In the second theory of commitment, Allen and Meyer (1996) specified three forms of commitment. Affective commitment refers to employees' identification with, emotional attachment to, and involvement in the organization, which is the type of commitment in their taxonomy that is theoretically most aligned with autonomous motivation. Gagné, Boies, Koestner, and Martens (2004) thus predicted that 
affective commitment would be facilitated by employees' autonomous motivation. They collected data from three sets of employees in varied organizations, assessing the external, introjected, identified, and intrinsic motivation of the participants as well as their affective commitment. In each sample, the researchers found the same pattern of correlations of intrinsic, identified, introjected, and external motivation with affective commitment that Gagné and Koestner (2002) had found when they related the types of motivation to O'Reilly and Chatman's measure of identification and internalization. Thus, the type of organizational commitment that encompasses accepting the organizational goals, being committed to the organization, and feeling engaged with and attached to the organization appear to be facilitated by autonomous motivation.

\section{SDT Research in Organizations}

Several studies have supported SDT as an approach to work motivation by confirming aspects of the theory within organizations. First, Eden (1975) reported a negative relation between the perception of extrinsic rewards and the amount of intrinsic motivation among kibbutz workers, and Deckop and Cirka (2000) found that the introduction of merit-pay programs in a non-profit organization led to decreased feelings of autonomy and intrinsic motivation, thus providing some indication that rewards can undermine intrinsic motivation in work settings. Further, Shirom, Westman, and Melamed (1999) found that pay-for-performance plans led to lower well-being in blue-collar workers, especially for those who felt their jobs were monotonous.

Second, studies have found relations between managerial autonomy support and positive work outcomes. For example, Deci et al. (1989) found that managerial autonomy support, defined as managers' acknowledging their subordinates' perspectives, providing relevant information in a non-controlling way, offering choice, and encouraging self-initiation rather than pressuring subordinates to behave in specified ways, was associated with employees' being more satisfied with their jobs, having a higher level of trust in corporate management, and displaying other positive work-related attitudes. In that study of a major U.S. corporation, some of the managers were then trained to be more autonomy supportive in their supervisory styles. The training consisted of managers spending a total of 6 days with a change agent over a 2- to 3-month period. The agent led group discussions and role-playing activities with the managers, organized around three themes: maximizing opportunities for employees to take initiative (make choices and solve problems), giving non-controlling informational feedback, and recognizing and accepting subordinates' perspectives (their needs and feelings). In addition, the agent accompanied each manager to one of his or her work group meetings to observe the process and provide feedback. The researchers found that the level of managers' autonomy support increased in the intervention sites relative to the control group sites and, even more importantly, that these changes radiated to their subordinates, who reported increases in perceptions of the quality of supervision, trust in the organization, and job-related satisfaction.

Third, studies have found that managers' autonomy support led to greater satisfaction of the needs for competence, relatedness, and autonomy and, in turn, to more job satisfaction, higher performance evaluations, greater persistence, greater acceptance of organizational change, and better psychological adjustment (Baard et al., 2004; Deci et al., 2001; Gagné et al., 2000; Ilardi, Leone, Kasser, \& Ryan, 1993; Kasser, Davey, \& Ryan, 1992). The Baard et al. study also showed that the general autonomous causality orientation predicted need satisfaction and positive work outcomes, and the Deci et al. study confirmed that basic psychological need satisfaction was important in a collectivist culture as well as an individualistic culture (see, also Chirkov, Ryan, Kim, \& Kaplan, 2003). 
Fourth, Blais and Brière (1992) found that managerial autonomy support positively predicted subordinates' autonomous motivation and, in turn, the quality of the subordinates' performance. Lynch, Plant, and Ryan (in press) found that when a major new program for handling patients was introduced into a state-run psychiatric hospital, staff members who perceived greater autonomy support from their supervisors showed greater internalized motivation for implementing the program than did those who experienced their supervisors as more controlling. Breaugh (1985) showed that feeling autonomous in one's job increased job involvement and quality of performance, which is consistent with the Sheldon and Elliot (1998) finding that autonomous motivation predicted greater effort and more goal attainment.

Fifth, as mentioned earlier, Gagné and Koestner (2002) and Gagné et al. (2004) found autonomous motivation to be related to organizational commitment as indexed by identification and internalization using O'Reilly and Chatman's (1986) measure and by affective commitment using Allen and Meyer's (1996) measure. With a 13-month longitudinal design, the researchers found that autonomous motivation at the beginning of the study predicted organizational commitment at the end, whereas initial commitment did not predict subsequent autonomous motivation. It thus seems that autonomous motivation is important if employees are to accept the organization's goals and be committed to working toward them.

Finally, a recent study by Bono and Judge (2003) showed that followers of transformational or visionary leaders were more likely to adopt autonomous goals than controlled goals in the workplace. These followers were also more satisfied with their jobs and more affectively committed to the organization. Because transformational leadership involves motivating through facilitating identification with the group, increasing follower self-efficacy, and linking work values to follower values (Shamir, Zakay, Breinin, \& Popper, 1998), it appears that transformational leaders support their followers' autonomy and allow satisfaction of the basic psychological needs.

Taken together, studies in organizations have provided support for the propositions that autonomysupportive (rather than controlling) work environments and managerial methods promote basic need satisfaction, intrinsic motivation, and full internalization of extrinsic motivation, and that these in turn lead to persistence, effective performance, job satisfaction, positive work attitudes, organizational commitment, and psychological well-being.

\section{The relation of autonomous motivation to effective performance}

Throughout the article we have made mention of studies examining the relation of types of motivation to effective performance. Research has indicated that understanding this relation requires differentiating performance outcomes in terms of whether the task is relatively simple, involving the tedious application of an algorithm, or is more difficult, involving flexibility, creativity, and heuristic problem solving (McGraw, 1978). Laboratory experiments as well as field studies in several domains have shown that autonomous motivation is associated with more effective performance on relatively complex tasks, whereas there is either no difference or a short-term advantage for controlled motivation when mundane tasks are involved (Amabile, 1982; Grolnick \& Ryan, 1987; McGraw \& McCullers, 1979). For example, Benware and Deci (1984) found autonomous motivation to be significantly superior to controlled motivation for facilitating conceptual understanding of text material, but the two types of motivation did not differ in promoting rote learning of facts contained within the reading. Other studies found that controlled motivation led to better performance on mundane tasks (Grolnick \& Ryan, 1987; McGraw, 1978), although Grolnick and Ryan reported that the advantage had worn off within a week.

Research by Koestner and Losier (2002) has highlighted another important difference, namely that intrinsic motivation yielded better performance on tasks that are interesting but that autonomous 
extrinsic motivation yielded better performance on tasks that are not in themselves interesting but that are important and require discipline or determination. Together, the studies suggest that autonomous motivation, consisting of a mix of intrinsic motivation and internalized extrinsic motivation, is superior in situations that include both complex tasks that are interesting and less complex tasks that require discipline. When a job involves only mundane tasks, however, there appears to be no performance advantage to autonomous motivation. Still, even in those situations, autonomous motivation will be associated with greater job satisfaction and well-being, as was found by Ilardi et al. (1993) in a study of employees with monotonous jobs in a shoe factory and by Shirom and colleagues (1999) in a study of blue-collar workers with mundane jobs. This implies that, overall, autonomous motivation is preferable in organizations because even with dull, boring jobs there is an advantage to autonomous motivation in terms of job satisfaction and well-being, which are likely to yield better attendance and lower turnover (Breaugh, 1985; Karasek \& Theorell, 1990; Matteson \& Ivancevich, 1987; Sherman, 1989).

Figure 2 summarizes the main elements of the SDT model of work motivation. These relations have been supported, though to differing degrees, by research in either organizations or other settings. In the next section we look more specifically at issues within the theory that would benefit from examination in work settings. These include tests of specific paths in the model as well as other more nuanced issues that can be derived from the theory.

\section{Research Agendas for the SDT Model of Work Motivation}

Although, as already noted, SDT is based on a strong empirical foundation, relatively few studies have tested the theory within organizational settings. In this section we present propositions that need to be

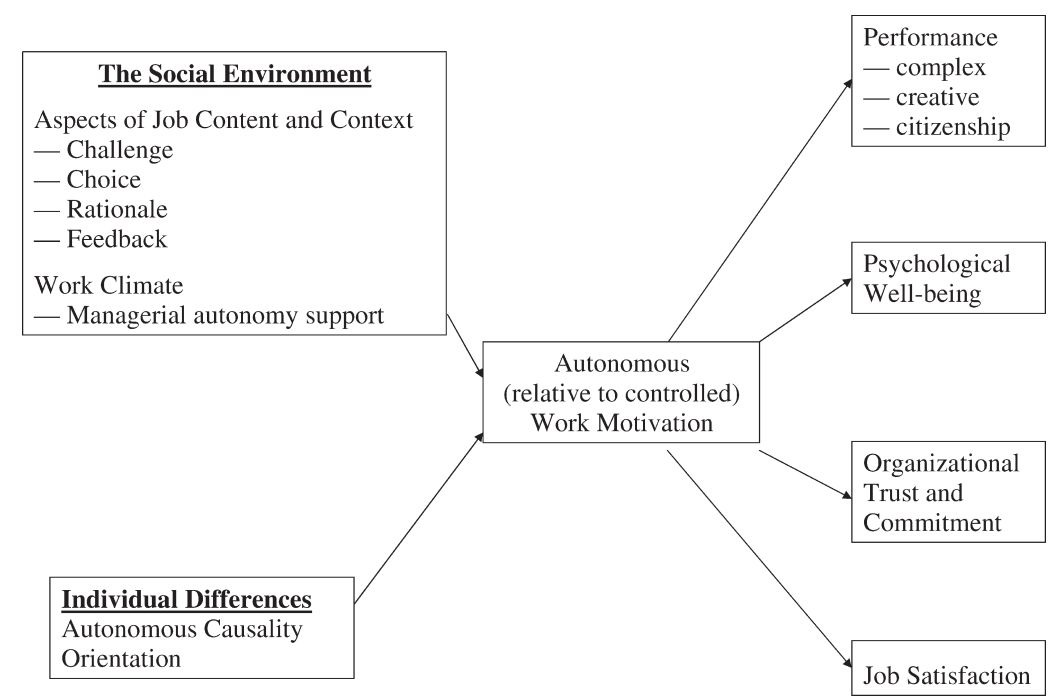

Figure 2. Summary model showing environmental factors (job content, job context, and work climate), and individual differences (causality orientation) as antecedents of autonomous motivation, as well as the work outcomes associated with autonomous motivation 
examined in work organizations even though they have been supported by laboratory experiments and field studies in other applied domains, including health care, education, and sport.

Proposition 1: Autonomous extrinsic motivation will be more effective in predicting persistence on uninteresting but effort-driven tasks, whereas intrinsic motivation will be more effective in predicting persistence on interesting tasks.

Self-determination theory is the only theory that has detailed the processes through which extrinsic motivation can become autonomous. It has proposed that the types of autonomous motivation (viz., intrinsic motivation and identified/integrated extrinsic motivation) will share many qualities, but it has nonetheless maintained that it is important to keep the concepts of intrinsic motivation and autonomous extrinsic motivation separate both theoretically and empirically. Specifically, the theory suggests that intrinsic motivation concerns experiencing activities as interesting and spontaneously satisfying, whereas autonomous extrinsic motivation concerns experiencing activities not as interesting but as personally important for one's self-selected aims and purposes. Empirically, the theory suggests the two types of autonomous motivation will be differentially effective in predicting various outcomes, with intrinsic motivation being a better predictor of behaviors that are interesting and enjoyable in their own right, whereas identified/integrated regulation will be more effective in predicting performance on tasks that require some discipline and concerted effort.

Koestner, Losier, Vallerand, and Carducci (1996) examined motivation in the political domain, assessing participants' intrinsic motivation and identified regulation for involvement in an important national referendum in Canada. The researchers found that intrinsic motivation was the better predictor of gathering information and being well informed about the issues involved with the referendum, but that identified regulation was a better predictor of actual voting behavior. When intrinsically interested in the issues, people became well informed, but only when they were motivated by the importance of the issues to themselves were they likely to actually exert the effort to go out and vote.

Exactly how intrinsic motivation versus well-internalized extrinsic motivation will be differentially predictive in the workplace is still to be determined, but it is an important issue with respect to SDT as a model of work motivation.

Proposition 2: Controlled motivation will yield poorer performance on heuristic tasks than autonomous motivation, but will lead to equal to or better short-term performance on algorithmic tasks.

Research in the laboratory and in educational settings has provided consistent support for this proposition. For example, (1) tangible rewards, which facilitate controlled motivation, have been found to diminish conceptual learning and effective problem solving (e.g., McGraw, 1978; McGraw \& McCullers, 1979); (2) tests and grades, which represent controlling motivators, have been shown to diminish deep processing and conceptual performance, but not rote memorization (Grolnick \& Ryan, 1987); and (3) competition, rewards, and evaluations, which tend to be controlling, have been found to decrease creativity (Amabile et al., 1990). In contrast, learning material in order to put it to active use (Benware \& Deci, 1984), evaluate its interest value (Grolnick \& Ryan, 1987), or attain intrinsic goals (Vansteenkiste et al., 2004) facilitated autonomous motivation, deep processing, and conceptual learning.

Concerning work organizations, one published study that used SDT concepts to examine work performance has treated it as a general concept, reflected in performance evaluations (Baard et al., 2004). That study showed that both the autonomy support of managers and the autonomous causality orientation of employees predicted better performance. However, that work did not differentiate performance, so future work that does so is needed.

Proposition 3: Autonomy-supportive work climates facilitate internalization of extrinsic motivation, resulting in more autonomous self-regulation of extrinsically motivated behavior. 
Central to the SDT model is the proposition that when a socially valued activity is prompted by extrinsic motivation in an autonomy-supportive social context people will tend to internalize and integrate the regulation of that behavior. In other words, when the social context supports autonomy, the level of people's identified and integrated motivation for the target activity or domain will increase.

This proposition has received support in both the field and lab. A study of smoking cessation showed that when health care providers were more autonomy supportive in their interpersonal style, patients showed greater internalization of motivation for smoking cessation, which in turn predicted greater cessation, biochemically validated (Williams et al., in press). In the laboratory study by Deci et al. (1994) reviewed earlier, the support of autonomy represented by specific characteristics of the social environment - namely, choice, rationale, and acknowledgment of feelings - also led to greater overall internalization and, more specifically, to more integration of the internalized regulations.

Thus, both field and lab studies have provided support for this key proposition. However, only one study has examined this in the workplace. Specifically, Lynch et al. (in press) found that autonomy support from managers of employees in a psychiatric hospital for children was associated with the employees' internalizing the motivation for carrying out a new program for treating the residential patients and with greater intrinsic job satisfaction. Further research is needed to relate autonomy support in the workplace to increases in autonomous motivation.

Similarly, the SDT model proposes that people high in the autonomous causality orientation would be more ready to internalize regulations for activities that are meaningful to them. A study of morbidly obese patients in a medically supervised weight loss program (Williams et al., 1996) provided some evidence for this, but it did not examine change scores, and the issue needs to be examined in the workplace as well.

Proposition 4: Specific aspects of jobs interact with the work climates to influence autonomous motivation for work.

Dozens of lab experiments have examined the effects of specific aspects of tasks and contexts on autonomous motivation. Many have identified aspects that undermine intrinsic motivation and deter internalization, including various reward structures (Deci et al., 1999), imposition of goals (Mossholder, 1980), and surveillance (Lepper \& Greene, 1975), while others have focused on characteristics that tend to enhance intrinsic motivation and facilitate internalization, including job characteristics (Gagné et al., 1997), acknowledgment (Deci et al., 1994), choice (Zuckerman et al., 1978), and positive feedback (Deci et al., 1975; Ryan, 1982). Examination of such factors represents an analogue to the study of job contents and contexts, but little research has been done to examine these specific factors identified by SDT research as having an effect on autonomous motivation.

Furthermore, laboratory experiments have shown that these specific factors interact with the interpersonal climate within which they are administered to affect intrinsic motivation and internalization (e.g., Koestner, Ryan, Bernieri, \& Holt, 1984; Ryan, 1982). In one such study, Ryan et al. (1983) found that, relative to a control group that received no rewards and no feedback, participants who received performance-contingent rewards administered in an autonomy-supportive interpersonal climate evidenced higher intrinsic motivation, whereas those who received performance-contingent rewards administered in a controlling interpersonal climate showed lower intrinsic motivation.

Just as factors such as rewards, choice, positive feedback, and surveillance can be thought of as being parallel to specific job aspects, the interpersonal climate can be thought of as being parallel to the work climate or organization climate. However, research needs to be done to examine the effects of the interaction of job aspects with work climates on both intrinsic motivation and internalization of extrinsic motivation. 
Proposition 5: Concrete managerial behaviors that support subordinates' autonomy in the workplace can be identified empirically.

Research on the effects of an autonomy-supportive managerial style has yielded a variety of positive work outcomes (e.g., Deci et al., 1989, 2001). In such studies, autonomy support, which is defined in terms of understanding and acknowledging the subordinates' perspectives, encouraging self-initiation, minimizing pressures and controls, and providing relevant information, has been measured as a general concept using psychometric instruments. Little work has been done in work settings to isolate concrete managerial behaviors that represent autonomy support, and such behaviors, when isolated, will need to be studied in terms of facilitating internalization and autonomous behavior among subordinates. The laboratory study by Deci et al. (1994) identified the behaviors of acknowledging others' perspectives, providing meaningful rationales, and minimizing controls as being autonomy supportive and as facilitating internalization and integration. Further, the field experiment by Deci et al. (1989) showed that training managers to maximize subordinates' opportunities to take initiative, provide informational feedback, and acknowledge the subordinates' perspectives improved subordinates' attitudes and trust in the corporation. Still, considerably more organization research exploring this issue needs to be done.

Proposition 6: Employees' autonomous causality orientations and autonomy-supportive work climates will have additive, independent positive effects on employees' autonomous motivation and positive work outcomes.

SDT proposes that people who are high in the autonomous causality orientation tend to be more autonomously motivated in a particular situation and to show positive performance and well-being outcomes. Similarly, people in social contexts that are autonomy supportive also display more autonomous motivation and positive consequences. This raises the issue of whether the so-called match hypothesis, which has been examined in organization settings with respect to other concepts such as need strength (e.g., Hackman \& Lawler, 1971), might apply to the concepts of autonomous and controlled causality orientations. In other words, might it be the case that people high in the autonomy orientation would evidence better outcomes in autonomysupportive contexts, whereas people high in the controlled orientation would do better in controlled contexts?

Research in medical settings indicated that that is not the case. For example, a study of obese patients (Williams et al., 1996) showed that patients who were high in the autonomy orientation were more autonomous in their motivation for losing weight and showed more maintained weight loss that patients low on the autonomy orientation. Further, patients who experienced more autonomysupportive health care climates also were more autonomous and had more positive outcomes. Thus, there were two main effects, and there was no evidence of an interaction between these variables. Further, the Black and Deci (2000) study discussed earlier found that students whose motivation was more controlled at the beginning of a semester showed substantial benefits when they had autonomysupportive instructors, further suggesting that the match hypothesis is not valid. Still, there has been no research examining this issue in work settings. Within organizational research, the work that comes closest to examining this issue is a study by Baard et al. (2004), which showed that both the autonomous orientation and autonomy support facilitated basic need satisfaction, which led to both better performance and greater well-being. The study showed two main effects on need satisfaction and outcomes, but it did not examine internalization of extrinsic motivation. Thus, it will be important to examine the effects of both work climates and causality orientations on internalization of extrinsic motivation in organizational settings. 


\section{The Relation of SDT to Other Organizational Behavior Research Questions}

SDT has been developed as a macro-theory of motivation. We now suggest that, because of its comprehensive nature, the theory might raise new empirical questions, suggest new directions for research, and provide a basis for integrating various phenomena within the field of organizational behavior. We provide just a few examples.

\section{Organizational citizenship}

Recent discussions of effective performance in organizations have emphasized the importance of considering organizational citizenship (Borman \& Motowidlo, 1993; Organ, 1988). This concerns voluntary behaviors that are not directly recognized by the formal reward structure but do promote organizational effectiveness. Examples include helping co-workers, formulating innovations, serving on committees, and helping to organize work group events (e.g., Podsakoff, MacKenzie, \& Bommer, 1996).

Although there is relatively little work relating SDT concepts to organizational citizenship, evidence does indicate that autonomous motivation promotes volunteering and other prosocial behaviors (e.g., Gagné, 2003) and thus, presumably, would also predict citizenship in organizations (Penner, Midili, \& Kegelmeyer, 1997). For example, Gagné (2003) conducted two studies examining the role of autonomy support on need satisfaction and prosocial behavior. One showed that parental support of college students' autonomy predicted satisfaction of the students' basic needs for competence, relatedness, and autonomy, which in turn predicted the amount the students engaged in prosocial activities such as giving blood and volunteering. The other study showed that the level of perceived autonomy support in a volunteer work organization related positively to need satisfaction of the volunteers, which in turn related positively to the amount they volunteered for the activity and negatively to their likelihood of quitting.

Greene-Demers, Pelletier, and Ménard (1997) reported that autonomous motivation predicted engagement in environmentally protective behaviors such as recycling, especially if the behaviors required substantial effort. Further, Pelletier et al. (1998) found that autonomous extrinsic motivation was more predictive of pro-environmental behaviors than was intrinsic motivation, supporting the point made by Losier and Koestner (1999) that uninteresting but important activities that require disciplined enactment are best promoted by integrated extrinsic motivation.

Numerous other studies have shown that conditions which tend to undermine autonomous motivation also tend to diminish prosocial behavior. For example, Fabes et al. (1989) found that rewarding children for helping undermined their subsequent helping behavior, and Kunda and Schwartz (1983) found that payments decreased undergraduates' helping behavior by undermining their internalized sense of moral commitment to help. Upton (1974) reported that committed blood donors who received a reward were subsequently less likely to donate compared to committed donors who were not offered a reward (see also Batson, Coke, Jasnoski, \& Hanson, 1978). Sobus (1995) studied mandatory volunteering programs in schools and argued that such programs rob people of their sense of self-determination.

SDT also provides a framework for integrating and extending Bolino's (1999) proposition that organizational citizenship behaviors (OCB) can be enacted either for altruistic or for impression management reasons. He proposed that $\mathrm{OCB}$ enacted for impression management reasons (e.g., ingratiation and self-promotion) may lead to different outcomes for organizations, such as having a less positive impact on overall organizational effectiveness, than does OCB enacted for altruistic reasons. What is 
referred to as impression management reasons are examples of controlled motivation, and what is referred to as altruistic reasons can be thought of as a type of autonomous motivation. Thus, the concepts of controlled and autonomous motivation could provide the basis for extending Bolino's formulation to consider additional factors in the social environment that would likely promote controlled versus autonomous motivations for engaging in OCB. Bolino proposed that when organizational politics are salient people will engage in OCB for impression management purposes, which is consistent with the SDT perspective. We would, however, propose extending this to the broader prediction that social contexts that are more controlling in whatever way-for example, because of certain reward structures or pressure from managers - would be likely to result in external or introjected motivations for OCB. That, we hypothesize, would lead to less long-term persistence at the OCBs.

To summarize, studies indicate that autonomous motivation predicts volunteering and prosocial behavior and it seems probable that autonomous motivation would also promote organizational citizenship. That conclusion is consistent with research by Smith, Organ, and Near (1983) showing that managers' supportive leadership led to greater organizational citizenship, and by O'Reilly and Chatman (1986) showing that organizational commitment related to engagement in organizational citizenship. By using SDT, the predictions could become broader, more refined, and better integrated than those in previous studies.

\section{The satisfaction-performance relation reconsidered}

As noted by Judge, Thoresen, Bono, and Patton (2001), research on the relation between performance and satisfaction has been a central concern to I/O psychologists for decades. Hundreds of studies have addressed the issue and many reviews have provided diverse summaries of the field. The meta-analysis by Judge et al. is the most comprehensive to date and shows again that there is a modest positive relation between job performance and job satisfaction. The authors noted, however, that substantial variability in the size of this relation has been found across studies and that the variability seems to be due to the way the concepts have been assessed and to other factors such as job complexity. The authors concluded that further research is needed, particularly studies that consider moderators or mediators of the relation between performance and satisfaction. We thus use the results of SDT-based research to speculate about this relation.

As already noted, recent motivation research has emphasized the importance of distinguishing between performance on interesting or important versus mundane or boring tasks (e.g., McGraw, 1978). Autonomous motivation has been found to be superior for promoting performance on jobs involving both complex tasks and personally important tasks requiring disciplined engagement, and it has been associated with satisfaction and adjustment on those jobs (e.g., Baard et al., 2004). In contrast, controlled motivation has been found to yield comparable or superior short-term performance on dull, boring tasks (e.g., Grolnick \& Ryan, 1987), although it has been associated with poorer adjustment and satisfaction on those jobs (e.g., Ilardi et al., 1993). In other words, with more interesting, complex, and important jobs, autonomous motivation has positive relations both to performance and to job satisfaction and well-being, whereas with mundane and boring tasks controlled motivation may have a short-term performance advantage but leads to poorer adjustment and well-being. This set of findings is potentially important for helping to clarify the satisfaction-performance relation. Specifically, it suggests that autonomous versus controlled motivations and the conditions that prompt

these motivations may moderate the link between satisfaction and performance on the job. In other words, when job conditions prompt autonomous motivation for work there will be a strong positive relation between performance and satisfaction, but when they prompt controlled motivation this relation will be absent. 
Our central speculation is that autonomous (versus controlled) motivation and the job content and context factors that promote autonomous (versus controlled) motivation will moderate the relation between job satisfaction and job performance. Because people tend to be autonomously motivated when a task is either interesting (and thus intrinsically motivating) or personally important (and thus autonomously extrinsically motivating), and when the work climate supports autonomy, we hypothesize that these are the conditions that will lead to a positive performance-satisfaction relation. In contrast, because people's motivation tends to be controlled when tasks are simple and dull and the work climate is controlling, we expect a low positive or negative correlation under these conditions.

Judge et al. (2001) presented a framework for understanding this relation in which job complexity was the most important substantive moderator of the relation. They concluded that when tasks were more complex there would be a stronger positive correlation between satisfaction and performance. We now suggest that our hypothesized moderation effect is consistent with that finding. Specifically, because complex tasks have the potential to be experienced as more challenging and meaningful they are likely to prompt autonomous motivation which is associated with high levels of both effective performance and job satisfaction. On the other hand, simpler, more mundane jobs are often structured to prompt controlled motivation, which is expected to lead to low job satisfaction even when there is effective performance.

The primary reason for using the concept of autonomous versus controlled motivation rather than just task complexity as the hypothesized moderator is that autonomous versus controlled motivation for the job integrates several important job content, job context, and work climate factors, as well as individual differences in general causality orientations, and we hypothesize that all of these other factors would moderate the relation. Thus, this hypothesis would be the basis for a research program examining the role of autonomous versus controlled motivation as a moderator of the performance-satisfaction relation.

When people are autonomously motivated at work they tend to experience their jobs as interesting or personally important, self-initiated, and endorsed by relevant others. When people perform effectively at these jobs, they experience satisfaction of the basic psychological needs and have positive attitudes toward their jobs. However, when they are controlled in their motivation-for example, when they are prompted by external or introjected contingencies to do boring tasks-effective performance is less likely to result in need satisfaction and reports of high levels of job satisfaction. A 10-week longitudinal study by Sheldon and Kasser (1998) provided some support for this reasoning. They found that autonomous versus controlled motivation moderated the relation between goal attainment and life satisfaction. Specifically, when participants were autonomously motivated in pursuing self-generated goals, there was a strong relation between goal attainment and life satisfaction, whereas, when participants were more controlled in their goal pursuits, there was no relation between goal attainment and life satisfaction.

To summarize, aspects of jobs such as complexity, challenge, importance, choice, and participation, as well as autonomy-supportive interpersonal climates and being high on the autonomous causality orientation, lead employees to be relatively autonomously motivated for their jobs. We suggest that this will result in their doing the jobs well and experiencing a high level of job satisfaction. In contrast, conditions that promote controlled motivation will yield less effective overall performance, especially on heuristic tasks, and the quality of performance is expected to be unrelated to job satisfaction. Thus, job characteristics, interpersonal climates, and causality orientations are all expected to influence people's autonomous versus controlled motivation, which in turn is hypothesized to moderate the bidirectional relation between job performance and job satisfaction.

\section{Reward effects revisited}

Organizational psychologists have long recognized the importance of intrinsic motivation in work organizations (e.g., Herzberg, 1968; McGregor, 1960) and have also recognized the power of 
contingent tangible extrinsic rewards for motivating behavior. As noted earlier, however, the Deci et al. (1999) meta-analysis of reward effects showed a strong overall negative effect of tangible rewards on intrinsic motivation, raising concerns about how intrinsic and extrinsic motivation would work together positively.

One of the most important results from studies examining the effects of rewards on intrinsic motivation is that the interpersonal climate within which rewards are administered has a significant influence on the rewards' effects. Specifically, when rewards are administered in an autonomy-supportive climate, they are less likely to undermine intrinsic motivation and, in some cases, can enhance intrinsic motivation. For example, Ryan et al. (1983) found that performance-contingent monetary rewards administered in an autonomy-supportive context enhanced intrinsic motivation relative to a no-reward, no-feedback control group, whereas those administered in a controlling context undermined intrinsic motivation. The research thus indicated that rewards used to acknowledge competence can have a positive effect if the climate is autonomy supportive. Further, research has shown that rewards must be perceived as equitable in order not to have negative effects (Adams, 1963). Together, such results suggest that incentive programs need to be designed to be equitable and to acknowledge effective performance without incorporating controlling elements such as competition among team-mates or pressure to 'meet the numbers.' Then, the rewards need to be administered by autonomy-supportive managers.

All of the studies of reward effects on intrinsic motivation have been done with the dichotomous conceptualization of intrinsic versus extrinsic motivation. Little research has examined reward effects with respect to the internalization of extrinsic motivation. The differentiated view of extrinsic motivation presented by SDT provides a basis for examining the effects of tangible rewards on motivation in a more rigorous and careful way that includes a consideration of the effects of rewards and work climates on internalization as well as intrinsic motivation. The field is in need of just such research.

\section{Autonomous Extrinsic Motivation in the Workplace}

Many studies indicate that autonomous motivation (i.e., intrinsic motivation and integrated extrinsic motivation) maximizes heuristic performance, citizenship, trust, commitment, satisfaction, and wellbeing. Intrinsic motivation has long been emphasized in the organizational literature. However, autonomous extrinsic motivation has not yet been considered by organizational psychologists and management theorists even though research reviewed earlier shows that, for uninteresting tasks requiring disciplined task engagement, autonomous extrinsic motivation may lead to the most effective performance.

Research suggests that autonomous work motivation is facilitated by environments in which jobs are interesting, challenging, and allow choice and in which the work climate is autonomy supportive, as well as by employees being high on the autonomous causality orientation. However, although the autonomous causality orientation has been consistently associated with autonomous task motivation and positive outcomes, there is little managers can do to affect subordinates' enduring individual differences, so focusing on how to change the environment to promote autonomous extrinsic motivation represents a more fruitful approach. To date, however, there has been relatively little research on promoting autonomous extrinsic motivation in organizations, and none of it has been longitudinal.

Based on numerous studies herein reviewed, it seems probable that many of the factors that enhance intrinsic motivation would also facilitate internalization of extrinsic motivation because these factors facilitate satisfaction of the needs for competence and autonomy which have consistently been found important for integrated extrinsic motivation as well as for intrinsic motivation. Thus, one could 
extrapolate from research in other domains (e.g., Williams et al., 1998) to hypothesize that conveying the importance of tasks and providing autonomy-supportive work climates would promote internalization of extrinsic motivation and benefit all employees, but as yet there is no clear evidence for this.

Many management theorists have recommended that jobs be enlarged to enhance intrinsic motivation (e.g., Lawler \& Hall, 1970). Horizontal enlargement involves expanding jobs so they will include more activities and have task configurations that people can take pride in, while vertical enlargement involves expanding jobs to include more planning, decision making, and problem solving (i.e., allowing people greater autonomy). It had been suggested that both could make work more interesting and challenging, which, in turn, should lead to enhanced intrinsic motivation (e.g., Csikszentmihalyi, 1975; Deci, 1975; Zuckerman et al., 1978). However, both should also convey the importance of the work which is critical for internalizing extrinsic motivation. Horizontally enlarged jobs give people a greater sense of the importance of their work because they can see how the various parts of the jobs fit together into a meaningful unit. Further, vertical enlargement, in which people have greater say over what they do, also conveys a sense of importance to their endeavors. Thus, because importance (rather than interest) is the basis for autonomous extrinsic motivation, job enlargement could enhance both types of autonomous motivation. Given that well-internalized extrinsic motivation appears to promote enhanced performance for aspects of people's work that are not interesting, it would seem important to explore the relation of job enlargement to autonomous extrinsic motivation as well as to intrinsic motivation. There is actually research by Parker, Wall, and Jackson (1997) that relates to our speculations about the relation of job enlargement to autonomous motivation. Specifically, they found that horizontally enlarging jobs by creating team-based assembly cells enhanced participants' understanding and acceptance of the company's strategy and vision, and that enlarging jobs both horizontally and vertically by providing the assembly cells with autonomous decision making not only led to greater strategic understanding and acceptance but also to greater engagement with the new roles and greater effort expenditure toward achieving the strategic vision.

Autonomy-supportive work climates are ones in which managers are able to take employees' perspectives, provide greater choice, and encourage self-initiation. Ample evidence suggests that this would enhance both intrinsic motivation and autonomous extrinsic motivation. However, as noted earlier, three additional work climate factors have been found to facilitate internalization. First, because internalization involves taking in a value, limit, contingency, or regulation, there must be some means, whether implicit or explicit, by which the structure or value to be internalized is presented in the situations. As an example, Deci et al. (1994) found that a meaningful rationale for doing an uninteresting behavior led people to internalize the value and regulation of the behavior. Second, people tend to feel resistance to doing an uninteresting task, and research has shown that acknowledging their perspective and feelings about the task promotes internalization and autonomous regulation (Deci et al., 1994; Koestner et al., 1984). For example, Deci et al. (1994) found that reflecting people's feelings of finding an important activity uninteresting facilitated integration of its value and regulation.

Third, as already noted, the need for relatedness plays a central role in internalization of values and regulations. Thus, structuring work to allow interdependence among employees and identification with work groups, as well as being respectful and concerned about each employee, may have a positive effect on internalization of autonomous motivation and work outcomes (van Knippenberg \& van Schie, 2000; Wall, Kemp, Jackson, \& Clegg, 1986). Although we have devoted relatively little attention to the issue of relatedness among work group members and between each member and his or her manager, there is evidence that effective work groups can facilitate internalization of extrinsic motivation and positive work outcomes. For example, James and Greenberg (1989) found that identifying with a group, which facilitates internalization of group values, led to enhanced performance.

Promoting autonomous extrinsic motivation in the workplace will no doubt involve enabling employees to experience meaningfulness, competence, self-determination, and impact at work 
(Thomas \& Velthouse, 1990; Spreitzer, 1995), all of which contribute to satisfaction of their basic psychological needs and promote autonomous motivation (Gagné et al., 1997) and commitment (Eby, Freeman, Rush, \& Lance, 1999). More detailed empirical examination of these issues seems warranted.

\section{Conclusion}

It is well established that use of salient extrinsic rewards to motivate work behavior can be deleterious to intrinsic motivation and can thus have negative consequences for psychological adjustment, performance on interesting and personally important activities, and citizenship behavior. However, research also clarifies ways in which tangible rewards can be used so as not to be detrimental to intrinsic motivation. Furthermore, self-determination theory has detailed the processes through which extrinsic motivation can become autonomous, and research suggests that intrinsic motivation (based in interest) and autonomous extrinsic motivation (based in importance) are both related to performance, satisfaction, trust, and well-being in the workplace.

When the interaction of intrinsic and extrinsic motivation was first identified, cognitive evaluation theory provided an explanation for the phenomenon. However, many organizational psychologists and management theorists found the theory of limited use with respect to promoting performance and satisfaction in work organizations. Self-determination theory, which incorporates CET but is more comprehensive, particularly with respect to extrinsic motivation, provides a fuller and more useful approach to understanding the motivational bases for effective organizational behavior. Because much of the support for SDT has come from laboratory experiments and field studies in domains other than work organizations, we outlined a research agenda that will be important for supporting the use of SDT as a theory of work motivation.

\section{Author biographies}

Marylène Gagné is currently Assistant Professor of Organizational Behavior at the John Molson School of Business, Concordia University, in Montreal, Canada. She received her PhD in social psychology at the University of Rochester in 2000. She is interested in the effects of managerial styles and organizational rewards on work motivation. She also researches the effect of different motivational styles on individual and group performance and well-being in work organizations.

Edward L. Deci is Professor of Psychology and Gowen Professor in the Social Sciences at the University of Rochester. He received an MBA from the Wharton School at the University of Pennsylvania, a Ph.D. in social psychology from Carnegie Mellon University, and was an interdisciplinary postdoctoral fellow at Stanford University. His primary interest is human motivation, and his work has focused on self-determination theory. He has authored or edited 10 books related to these topics.

\section{References}

Adams, J. S. (1963). Toward an understanding of inequity. Journal of Abnormal and Social Psychology, 67, 422-436.

Alderfer, C. P. (1972). Existence, relatedness, and growth. New York: Free Press. 
Allen, N. J., \& Meyer, J. P. (1996). Affective, continuance, and normative commitment to the organization: an examination of construct validity. Journal of Vocational Behavior, 49, 252-276.

Amabile, T. M. (1982). Social psychology of creativity: a consensual assessment technique. Journal of Personality and Social Psychology, 43, 997-1013.

Amabile, T. M., DeJong, W., \& Lepper, M. R. (1976). Effects of externally imposed deadlines on subsequent intrinsic motivation. Journal of Personality and Social Psychology, 34, 92-98.

Amabile, T. M., Goldfarb, P., \& Brackfield, S. C. (1990). Social influences on creativity: evaluation, coaction, and surveillance. Creativity Research Journal, 3, 6-21.

Ambrose, M. L., \& Kulik, C. T. (1999). Old friends, new faces: motivation research in the 1990s. Journal of Management, 25, 231-292.

Atkinson, J. W. (1964). An introduction to motivation. Princeton, NJ: Van Nostrand.

Baard, P. P., Deci, E. L., \& Ryan, R. M. (2004). The relation of intrinsic need satisfaction to performance and wellbeing in two work settings. Journal of Applied Social Psychology, 34, 2045-2068.

Bandura, A. (1986). Social foundations of thought and action: A social cognitive theory. Englewood Cliffs, NJ: Prentice-Hall.

Batson, C. D., Coke, J. S., Jasnoski, M. L., \& Hanson, M. (1978). Buying kindness: effect of an extrinsic incentive for helping on perceived altruism. Personality and Social Psychology Bulletin, 4, 86-91.

Baumeister, R., \& Leary, M. R. (1995). The need to belong: desire for interpersonal attachments as a fundamental human motivation. Psychological Bulletin, 117, 497-529.

Benware, C., \& Deci, E. L. (1984). Quality of learning with an active versus passive motivational set. American Educational Research Journal, 21, 755-765.

Black, A. E., \& Deci, E. L. (2000). The effects of instructors' autonomy support and students' autonomous motivation on learning organic chemistry: a self-determination theory perspective. Science Education, 84, 740-756.

Blais, M. R., \& Brière, N. M. (1992). On the mediational role of feelings of self determination in the workplace: further evidence and generalization. Manuscript, University of Quebec at Montreal.

Bolino, M. C. (1999). Citizenship and impression management: good soldiers or good actors? Academy of Management Review, 24, 82-98.

Bono, J. E., \& Judge, T. A. (2003). Self-concordance at work: understanding the motivational effects of transformational leaders. Academy of Management Journal, 46, 554-571.

Borman, W. C., \& Motowidlo, S. J. (1993). Expanding the criterion domain to include elements of contextual performance. In N. Schmitt, \& W. C. Borman (Eds.), Personnel selection in organizations (pp. 71-98). San Francisco, CA: Jossey-Bass.

Breaugh, J. A. (1985). The measurement of work autonomy. Human Relations, 38, 551-570.

Calder, B. J., \& Staw, B. M. (1975). The interaction of intrinsic and extrinsic motivation: some methodological notes. Journal of Personality and Social Psychology, 31, 76-80.

Chirkov, V., Ryan, R. M., Kim, Y., \& Kaplan, U. (2003). Differentiating autonomy from individualism and independence: a self-determination theory perspective on internalization of cultural orientations and wellbeing. Journal of Personality and Social Psychology, 84, 97-109.

Csikszentmihalyi, M. (1975). Beyond boredom and anxiety. San Francisco, CA: Jossey-Bass.

Danner, F. W., \& Lonky, E. (1981). A cognitive-developmental approach to the effects of rewards on intrinsic motivation. Child Development, 52, 1043-1052.

deCharms, R. (1968). Personal causation: The internal affective determinants of behavior. New York: Academic Press.

Deci, E. L. (1971). Effects of externally mediated rewards on intrinsic motivation. Journal of Personality and Social Psychology, 18, 105-115.

Deci, E. L. (1975). Intrinsic motivation. New York: Plenum.

Deci, E. L. (1976). Notes on the theory and metatheory of intrinsic motivation. Organizational Behavior and Human Performance, 15, 130-145.

Deci, E. L., Cascio, W. F., \& Krusell, J. (1975). Cognitive evaluation theory and some comments on the Calder and Staw critique. Journal of Personality and Social Psychology, 31, 81-85.

Deci, E. L., Connell, J. P., \& Ryan, R. M. (1989). Self-determination in a work organization. Journal of Applied Psychology, 74, 580-590.

Deci, E. L., Eghrari, H., Patrick, B. C., \& Leone, D. R. (1994). Facilitating internalization: the self-determination theory perspective. Journal of Personality, 62, 119-142.

Deci, E. L., Koestner, R., \& Ryan, R. M. (1999). A meta-analytic review of experiements examining the effects of extrinsic rewards on intrinsic motivation. Psychological Bulletin, 125, 627-668. 
Deci, E. L., \& Ryan, R. M. (1980). The empirical exploration of intrinsic motivational processes. In L. Berkowitz (Ed.), Advances in experimental social psychology (Vol. 13, pp. 39-80). New York: Academic Press.

Deci, E. L., \& Ryan, R. M. (1985a). Intrinsic motivation and self-determination in human behavior. New York: Plenum.

Deci, E. L., \& Ryan, R. M. (1985b). The general causality orientations scale: self-determination in personality. Journal of Research in Personality, 19, 109-134.

Deci, E. L., \& Ryan, R. M. (2000). The 'what' and 'why' of goal pursuits: human needs and the self-determination of behavior. Psychological Inquiry, 11, 227-268.

Deci, E. L., Ryan, R. M., Gagné, M., Leone, D. R., Usunov, J., \& Kornazheva, B. P. (2001). Need satisfaction, motivation, and well-being in the work organizations of a former Eastern Bloc country. Personality and Social Psychology Bulletin, 27, 930-942.

Deckop, J. R., \& Cirka, C. C. (2000). The risk and reward of a double-edged sword: effects of merit-pay programs on intrinsic motivation. Nonprofit and Voluntary Sector Quarterly, 29, 400-418.

Dworkin, G. (1988). The theory and practice of autonomy. New York: Cambridge University Press.

Eby, L. T., Freeman, D. M., Rush, M. C., \& Lance, C. E. (1999). Motivational bases of affective organizational commitment: a partial test of an integrative theoretical model. Journal of Occupational and Organizational Psychology, 72, 463-483.

Eden, D. (1975). Intrinsic and extrinsic rewards and motives: replication and extension with Kibbutz workers. Journal of Applied Social Psychology, 5, 348-361.

Ellemers, N., de Gilder, D., \& Haslam, S. A. (2004). Motivating individuals and groups at work: a social identity perspective on leadership and group performance. Academy of Management Review, 29, 459-478.

Erez, M., Gopher, D., \& Arzi, N. (1990). Effects of goal difficulty, self-set goals, and monetary rewards on dual task performance. Organizational Behavior and Human Decision Processes, 47, 247-269.

Fabes, R. A., Fultz, J., Eisenberg, N., May-Plumlee, T., \& Christopher, F. S. (1989). Effects of rewards on children's prosocial motivation: a socialization study. Developmental Psychology, 25, 509-515.

Fisher, C. D. (1978). The effects of personal control, competence, and extrinsic reward systems on intrinsic motivation. Organizational Behavior and Human Performance, 21, 273-288.

Frese, M. (1989). Theoretical models of control and health. In S. L. Sauter, J. J. Hurell Jr., \& C. L. Cooper (Eds.), Job control and worker health (pp. 107-128). Chichester, U.K.: Wiley.

Frese, M. (2001). Personal initiative (PI): the theoretical concept and empirical findings. In M. Erez, U. Kleinbeck, \& H. Thierry (Eds.), Work motivation in the context of a globalizing economy (pp. 99-110). Mahwah, NJ: Erlbaum.

Frese, M., \& Sabini, J. (Eds.). (1991). Goal directed behavior: The concept of action in psychology. Hillsdale, NJ: Erlbaum.

Gagné, M. (2003). The role of autonomy support and autonomy orientation in the engagement of prosocial behavior. Motivation and Emotion, 27, 199-223.

Gagné, M., Boies, K., Koestner, R., \& Martens, M. (2004). How work motivation is related to organizational commitment: a series of organizational studies. Manuscript, Concordia University.

Gagné, M., \& Koestner, R. (2002). Self-determination theory as a framework for understanding organizational commitment. Paper presented at the annual meeting of the Society for Industrial and Organizational Psychology, Toronto, Canada.

Gagné, M., Koestner, R., \& Zuckerman, M. (2000). Facilitating the acceptance of organizational change: the importance of self-determination. Journal of Applied Social Psychology, 30, 1843-1852.

Gagné, M., Ryan, R. M., \& Bargmann, K. (2003). Autonomy support and need satisfaction in the motivation and well-being of gymnasts. Journal of Applied Sport Psychology, 15, 372-390.

Gagné, M., Senécal, C., \& Koestner, R. (1997). Proximal job characteristics, feelings of empowerment, and intrinsic motivation: a multidimensional model. Journal of Applied Social Psychology, 27, 1222-1240.

Greene-Demers, I., Pelletier, L. G., \& Ménard, S. (1997). The impact of behavioral difficult on the saliency of the association between self-determined motivation and environmental behaviors. Canadian Journal of Behavioural Science, 29, 157-166.

Grolnick, W. S., \& Ryan, R. M. (1987). Autonomy in children's learning: an experimental and individual difference investigation. Journal of Personality and Social Psychology, 52, 890-898.

Grolnick, W. S., \& Ryan, R. M. (1989). Parent styles associated with children's self-regulation and competence in school. Journal of Educational Psychology, 81, 143-154.

Hacker, W. (1994). Action regulation theory and occupational psychology: review of German empirical research since 1987. German Journal of Psychology, 18, 91-120. 
Hackman, J. R., \& Lawler, E. E. (1971). Employee reactions to job characteristics. Journal of Applied Psychology, $55,259-286$.

Hackman, J. R., \& Oldham, G. R. (1980). Work redesign. Reading, MA: Addison-Wesley.

Harlow, H. F. (1958). The nature of love. American Psychologist, 13, 673-685.

Heider, F. (1958). The psychology of interpersonal relations. New York: Wiley.

Herzberg, F. (1966) Work and the nature of man. Cleveland, OH: World.

Herzberg, F. (1968). One more time: how do you motivate employees? Harvard Business Review, 46, 53-62.

Hodgins, H. S., Koestner, R., \& Duncan, N. (1996). On the compatibility of autonomy and relatedness. Personality and Social Psychology Bulletin, 22, 227-237.

Ilardi, B. C., Leone, D., Kasser, T., \& Ryan, R. M. (1993). Employee and supervisor ratings of motivation: main effects and discrepancies associated with job satisfaction and adjustment in a factory setting. Journal of Applied Social Psychology, 23, 1789-1805.

James, K., \& Greenberg, J. (1989). In-group salience, intergroup comparisons, and individual performance and self-esteem. Personality and Social Psychology Bulletin, 15, 604-616.

Johns, G., Xie, J. L., \& Fang, Y. (1992). Mediating and moderating effects in job design. Journal of Management, $18,657-676$.

Joussemet, M., Koestner, R., Lekes, N., \& Houlfort, N. (2004). Introducing uninteresting tasks to children: a comparison of the effects of rewards and autonomy support. Journal of Personality, 72, 139-166.

Judge, T. A., Thoresen, C. J., Bono, J. E., \& Patton, G. K. (2001). The job satisfaction job performance relationship: a qualitative and quantitative review. Psychological Bulletin, 127, 376-407.

Kanfer, R. (1987). Task-specific motivation: an integrative approach to issues of measurement, mechanisms, processes, and determinants. Journal of Social and Clinical Psychology, 5, 237-264.

Kanfer, R., \& Ackerman, P. L. (1989). Motivation and cognitive abilities: an integrative/aptitude-treatment interaction approach to skill acquisition. Journal of Applied Psychology, 74, 657-690.

Kanfer, R., \& Ackerman, P. L. (2004). Aging, adult development, and work motivation. Academy of Management Review, 29, 440-458.

Kehr, H. M. (2004). Integrating implicit motives, explicit motives, and perceived abilities: the compensatory model of work motivation and volition. Academy of Management Review, 29, 479-499.

Karasek, R., \& Theorell, T. (1990). Healthy work: Stress, productivity, and the reconstruction of working life. New York: Basic Books.

Kasser, T., Davey, J., \& Ryan, R. M. (1992). Motivation and employee-supervisor discrepancies in a psychiatric vocational rehabilitation setting. Rehabilitation Psychology, 37, 175-187.

Kelman, H. (1958). Compliance, identification, and internalization: three processes of attitude change. Conflict Resolution, 2, 51-60.

Kirkpatrick, D. (1985). How to manage change effectively. San Franscisco, CA: Jossey-Bass.

Koestner, R., Bernieri, F., \& Zuckerman, M. (1992). Self-determination and consistency between attitudes, traits, and behaviors. Personality and Social Psychology Bulletin, 18, 52-59.

Koestner, R., \& Losier, G. F. (2002). Distinguishing three ways of being internally motivated: a closer look at introjection, identification, and intrinsic motivation. In E. L. Deci, \& R. M. Ryan (Eds.), Handbook of self-determination research (pp. 101-121). Rochester, NY: University of Rochester Press.

Koestner, R., Losier, G. F., Vallerand, R. J., \& Carducci, D. (1996). Identified and introjected forms of political internalization: extending self-determination theory. Journal of Personality and Social Psychology, 70, 10251036.

Koestner, R., Ryan, R. M., Bernieri, F., \& Holt, K. (1984). Setting limits on children's behavior: the differential effects of controlling vs. informational styles on intrinsic motivation and creativity. Journal of Personality, 52, 231-248.

Kunda, Z., \& Schwartz, S. H. (1983). Undermining intrinsic moral motivation: external reward and selfpresentation. Journal of Personality and Social Psychology, 45, 763-771.

Latham, G. P., Erez, M., \& Locke, E. A. (1988). Resolving scientific disputes by the joint design of crucial experiments by the antagonists: application to the Erez-Latham dispute regarding participation in goal setting. Journal of Applied Psychology, 73, 753-772.

Lawler, E. E. III, \& Hall, D. T. (1970). Relationship of job characteristics to job involvement, satisfaction, and intrinsic motivation. Journal of Applied Psychology, 54, 305-312.

Lepper, M. R., \& Greene, D. (1975). Turning play into work: effects of adult surveillance and extrinsic rewards on children's intrinsic motivation. Journal of Personality and Social Psychology, 31, 479-486.

Lewin, K. (1936). Principles of topological psychology. New York: McGraw-Hill. 
Locke, E. A. (1968). Toward a theory of task motivation and incentives. Organizational Behavior and Human Performance, 3, 157-189.

Locke, E. A., \& Latham, G. P. (1990). A theory of goal setting and task performance. Englewood Cliffs, NJ: Prentice-Hall.

Losier, G. F., \& Koestner, R. (1999). Intrinsic versus identified regulation in distinct political campaigns: the consequences of following politics for pleasure versus personal meaningfulness. Personality and Social Psychology Bulletin, 25, 287-298.

Lynch, M. F., Jr, Plant, R., \& Ryan, R. M. (in press). Psychological need satisfaction, motivation, attitudes, and well-being among psychiatric hospital staff and patients. Professional Psychology.

Maslow, A. H. (1954). Motivation and personality. New York: Harper \& Row.

Matteson, M. T., \& Ivancevich, J. M. (1987). Controlling work stress: Effective human resource and management strategies. San Francisco, CA: Jossey-Bass Inc.

McClelland, D. C., \& Burnham, D. H. (1976). Power is the great motivator. Harvard Business Review, 54, 100-110.

McGraw, K. O. (1978). The detrimental effects of reward on performance: a literature review and a prediction model. In M. R. Lepper, \& D. Greene (Eds.), The hidden costs of reward (pp. 33-60). Hillsdale, NJ: Erlbaum.

McGraw, K. O., \& McCullers, J. C. (1979). Evidence of a detrimental effect of extrinsic incentives on breaking a mental set. Journal of Experimental Social Psychology, 15, 285-294.

McGregor, D. (1960). The human side of enterprise. New York: McGraw-Hill.

Miller, G. A., Galanter, E., \& Pribram, K. H. (1960). Plans and the structure of behavior. New York: Holt, Rinehart, \& Winston.

Miner, J. B. (1990). The role of values in defining the 'goodness' of theories in organizational science. Organizational Studies, 11, 161-178.

Mitchell, T. R. (1974). Expectancy models of satisfaction, occupational preference and effort: a theoretical, methodological and empirical appraisal. Psychological Bulletin, 81, 1053-1077.

Mossholder, K. W. (1980). Effects of externally mediated goal setting on intrinsic motivation: a laboratory experiment. Journal of Applied Psychology, 65, 202-210.

O'Reilly, C., \& Chatman, J. (1986). Organizational commitment and psychological adjustment: the effects of compliance, identification, and internalization on prosocial behavior. Journal of Applied Psychology, 71, 492-499.

Organ, D. W. (1988). Organizational citizenship behavior: The good soldier syndrome. Lexington, MA: Lexington Books.

Parker, S. K., Wall, T. D., \& Jackson, P. R. (1997). 'That's not my job': developing flexible employee work orientations. Academy of Management Journal, 40, 899-929.

Pelletier, L. G., Tuson, K. M., Greene-Demers, I., Noels, K., \& Beaton, A. M. (1998). Why are you doing things for the environment? The Motivation Toward the Environmental Scale (MTES). Journal of Applied Social Psychology, 28, 437-468.

Penner, L. A., Midili, A. R., \& Kegelmeyer, J. (1997). Beyond job attitudes: a personality and social psychology perspective on the causes of organizational citizenship behavior. Human Performance, 10, 111-131.

Podsakoff, P. M., MacKenzie, S. B., \& Bommer, W. H. (1996). Transformational leader behaviors and substitutes for leadership as determinants of employee satisfaction, commitment, trust, and organizational citizenship behaviors. Journal of Management, 22, 259-298.

Porter, L. W., \& Lawler, E. E. III. (1968). Managerial attitudes and performance. Homewood, IL: Irwin-Dorsey.

Reis, H. T., Sheldon, K. M., Gable, S. L., Roscoe, J., \& Ryan, R. M. (2000). Daily well-being: the role of autonomy, competence, and relatedness. Personality and Social Psychology Bulletin, 26, 419-435.

Ryan, R. M. (1982). Control and information in the intrapersonal sphere: an extension of cognitive evaluation theory. Journal of Personality and Social Psychology, 43, 450-461.

Ryan, R. M., \& Connell, J. P. (1989). Perceived locus of causality and internalization: examining reasons for acting in two domains. Journal of Personality and Social Psychology, 57, 749-761.

Ryan, R. M., Connell, J. P., \& Deci, E. L. (1985). A motivational analysis of self-determination and self-regulation in education. In C. Ames, \& R. E. Ames (Eds.), Research on motivation in education: The classroom milieu (pp. 13-51). New York: Academic Press.

Ryan, R. M., \& Deci, E. L. (2000). Self-determination theory and the facilitation of intrinsic motivation, social development, and well-being. American Psychologist, 55, 68-78.

Ryan, R. M., \& Deci, E. L. (2002). On assimilating identities to the self: a self-determination theory perspective on internalization and integrity within cultures. In M. R. Leary, \& J. P. Tangney (Eds.), Handbook of self and identity (pp. 255-273). New York: Guilford. 
Ryan, R. M., Mims, V., \& Koestner, R. (1983). Relation of reward contingency and interpersonal context to intrinsic motivation: a review and test using cognitive evaluation theory. Journal of Personality and Social Psychology, 45, 736-750.

Ryan, R. M., Sheldon, K. M., Kasser, T., \& Deci, E. L. (1996). All goals were not created equal: an organismic perspective on the nature of goals and their regulation. In P. M. Gollwitzer, \& J. A. Bargh (Eds.), The psychology of action: Linking cognition and motivation to behavior (pp. 7-26). New York: Guilford.

Salancik, G. R., \& Pfeffer, J. (1977). An examination of need-satisfaction models of job attitudes. Administrative Science Quarterly, 22, 427-456.

Scott, W. E. (1975). The effects of extrinsic rewards on 'intrinsic motivation': a critique. Organizational Behavior and Human Performance, 14, 117-129.

Shamir, B., Zakay, E., Breinin, E., \& Popper, M. (1998). Correlates of charismatic leader behavior in military units: subordinates' attitudes, unit characteristics and superiors' appraisals of leader performance. Academy of Management Journal, 41, 387-409.

Sheldon, K. M., \& Elliot, A. J. (1998). Not all personal goals are 'personal': comparing autonomous and controlling goals on effort and attainment. Personality and Social Psychology Bulletin, 24, 546-557.

Sheldon, K. M., \& Elliot, A. J. (1999). Goal striving, need-satisfaction, and longitudinal well-being: the self-concordance model. Journal of Personality and Social Psychology, 76, 482-497.

Sheldon, K. M., \& Kasser, T. (1998). Pursuing personal goals: skills enable progress but not all progress is beneficial. Personality and Social Psychology Bulletin, 24, 1319-1331.

Sheldon, K. M., Ryan, R. M., Deci, E. L., \& Kasser, T. (2004). The independent effects of goal contents and motives on well-being: it's both what you pursue and why you pursue it. Personality and Social Psychology Bulletin, 30, 475-486.

Sherman, J. D. (1989). Technical supervision and turnover among engineers and technicians: influencing factors in the work environment. Group and Organization Studies, 14, 411-421.

Shirom, A., Westman, M., \& Melamed, S. (1999). The effects of pay systems on blue-collar employees' emotional distress: the mediating effects of objective and subjective work monotony. Human Relations, 52, $1077-1097$.

Smith, W. E. (1975). The effect of anticipated vs. unanticipated social reward on subsequent intrinsic motivation. Dissertation, Cornell University.

Smith, C. A., Organ, D. W., \& Near, J. P. (1983). Organizational citizenship behavior: its nature and antecedents. Journal of Applied Psychology, 68, 653-663.

Sobus, M. S. (1995). Mandating community service: psychological implications of requiring prosocial behavior. Law and Psychology Review, 19, 153-182.

Spreitzer, G. M. (1995). Psychological empowerment in the workplace: dimensions, measurement, and validation. Academy of Management Journal, 38, 1442-1465.

Thomas, K. W., \& Velthouse, B. A. (1990). Cognitive elements of empowerment: an 'interpretive' model of intrinsic task motivation. Academy of Management Review, 15, 666-681.

Tolman, E. C. (1932). Purposive behavior in animals and men. New York: Century.

Upton, W. E. III. (1974). Altruism, attribution and intrinsic motivation in the recruitment of blood donors. In Selected readings in donor recruitment (Vol. 2, pp. 7-38). Washington, DC: American National Red Cross.

Vallerand, R. J. (1997). Toward a hierarchical model of intrinsic and extrinsic motivation. In M. P. Zanna (Ed.), Advances in experimental social psychology (Vol. 29, pp. 271-360). San Diego, CA: Academic Press.

Vallerand, R. J., \& Fortier, M. S. (1998). Measures of intrinsic and extrinsic motivation in sport and physical activity: a review and critique. In J. Duda (Ed.), Advancements in sport and exercise psychology measurement (pp. 83-100). Morgantown, WV: Fitness Information Technology.

van Knippenberg, D., \& van Schie, E. C. M. (2000). Foci and correlates of organizational identification. Journal of Occupational and Organizational Psychology, 73, 137-147.

Vansteenkiste, M., Simons, J., Lens, W., Sheldon, K. M., \& Deci, E. L. (2004). Motivating learning, performance, and persistence: the synergistic effects of intrinsic goal contents and autonomy-supportive contexts. Journal of Personality and Social Psychology, 87, 246-260.

Vroom, V. H. (1964). Work and motivation. New York: Wiley.

Wall, T. D., Kemp, N. J., Jackson, P. R., \& Clegg C. W. (1986). Outcomes of autonomous workgroups: a long-term field experiment. Academy of Management Journal, 29, 280-304.

White, R. W. (1959). Motivation reconsidered: the concept of competence. Psychological Review, 66, $297-333$.

Williams, G. C., \& Deci, E. L. (1996). Internalization of biopsychosocial values by medical students: a test of selfdetermination theory. Journal of Personality and Social Psychology, 70, 767-779.

Williams, G. C., Deci, E. L., \& Ryan, R. M. (1998). Building health-care partnerships by supporting autonomy: promoting maintained behavior change and positive health outcomes. In A. L. Suchman, P. Hinton-Walker, \& 
R. Botelho (Eds.), Partnerships in healthcare: Transforming relational process (pp. 67-87). Rochester, NY: University of Rochester Press.

Williams, G. C., Grow, V. M., Freedman, Z. R., Ryan, R. M., \& Deci, E. L. (1996). Motivational predictors of weight loss and weight-loss maintenance. Journal of Personality and Social Psychology, 70, 115-126.

Williams, G. C., McGregor, H. A., Sharp, D., Levesque, C., Kouides, R. W., Ryan, R. M., \& Deci, E. L. (in press). Testing a self-determination theory intervention for motivating tobacco cessation: supporting autonomy and competence in a clinical trial. Health Psychology.

Zuckerman, M., Porac, J., Lathin, D., Smith, R., \& Deci, E. L. (1978). On the importance of self-determination for intrinsically motivated behavior. Personality and Social Psychology Bulletin, 4, 443-446. 